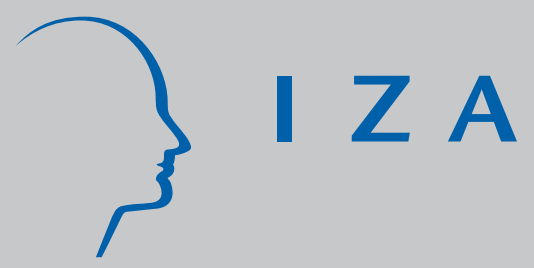

IZA DP No. 365

Qualifications, Discrimination, or Assimilation? An Extended Framework for Analysing Immigrant Wage Gaps

Helena Skyt Nielsen

Michael Rosholm

Nina Smith

Leif Husted

September 2001 


\title{
Qualifications, Discrimination, or Assimilation? An Extended Framework for Analysing Immigrant Wage Gaps
}

\author{
Helena Skyt Nielsen \\ CIM, CLS and Aarhus School of Business \\ Michael Rosholm \\ CIM, CLS, University of Aarhus, and IZA, Bonn \\ Nina Smith \\ CIM, CLS, Aarhus School of Business, and IZA, Bonn \\ Leif Husted \\ CIM and Institute of Local Government Studies, Copenhagen \\ Discussion Paper No. 365
September 2001 \\ IZA \\ P.O. Box 7240 \\ D-53072 Bonn \\ Germany \\ Tel.: +49-228-3894-0 \\ Fax: +49-228-3894-210 \\ Email: iza@iza.org
}

This Discussion Paper is issued within the framework of IZA's research area Mobility and Flexibility of Labor Markets. Any opinions expressed here are those of the author(s) and not those of the institute. Res earch disseminated by IZA may include views on policy, but the institute itself takes no institutional policy positions.

The Institute for the Study of Labor (IZA) in Bonn is a local and virtual international research center and a place of communication between science, politics and business. IZA is an independent, nonprofit limited liability company (Gesellschaft mit beschränkter Haftung) supported by the Deutsche Post AG. The center is associated with the University of Bonn and offers a stimulating research environment through its research networks, research support, and visitors and doctoral programs. IZA engages in (i) original and internationally competitive research in all fields of labor economics, (ii) development of policy concepts, and (iii) dissemination of research results and concepts to the interested public. The current research program deals with (1) mobility and flexibility of labor markets, (2) internationalization of labor markets and European integration, (3) the welfare state and labor markets, (4) labor markets in transition, (5) the future of work, (6) project evaluation and (7) general labor economics.

IZA Discussion Papers often represent preliminary work and are circulated to encourage discussion. Citation of such a paper should account for its provisional character. 
IZA Discussion Paper No. 365

September 2001

\section{ABSTRACT}

\section{Qualifications, Discrimination, or Assimilation? An Extended Framework for Analysing Immigrant Wage Gaps*}

In this paper, we analyze immigrant wage gaps and propose an extension of the traditional wage decomposition technique, which is a synthesis from two strains of literature on ethnic/immigrant wage differences, namely the 'assimilation literature' and the 'discrimination literature'. We estimate separate wage equations for natives and a number of immigrant groups using panel data sample selection models. Based on the estimations, we find that the immigrant wage gap is caused by a lack of qualifications and incomplete assimilation, and that a large fraction of that gap would disappear if only immigrants could find employment and thus accumulate work experience.

JEL Classification: J15, J16, J31, J71

Keywords: Wage assimilation, immigrants, wage gap, panel data sample selection model

Michael Rosholm

Department of Economics

University of Aarhus, Bld. 350

8000 Aarhus

Denmark

Tel.: +45 89421559

Fax: +4586136334

Email:mrosholm@econ.au.dk

\footnotetext{
* The project has been supported financially by the Danish Research Agency (the FREJA grant) and TSER. We are grateful for comments from several seminar and conference participants, and for the research assistance done by Thomas $\mathrm{H}$. Jensen.
} 


\section{Introduction}

In most countries immigrants have lower wage rates compared to natives. This phenomenon may have several causes; it can be caused by differences in 'standard' human capital, also denoted qualifications; it can be due to differences in host country specific human capital - a hopefully transitory component, whose gradual disappearance is called 'assimilation'. Finally, the differences in wages between immigrants and natives may be a result of discrimination, that is, differences in returns to the variables determining wages.

There are two strains of empirical literature, which may be useful for analyzing differences in wages between immigrants and natives; the 'discrimination' literature based on wage decompositions a la Oaxaca (1973), and the 'assimilation' literature, which was first introduced by Chiswick (1978). The first methodology allows a decomposition of observed wage differences into components due to qualifications and discrimination, while the second methodology allows identification of an assimilation profile and an indication of whether immigrants eventually 'catch up' to the wages of natives. The first methodology is typically used when looking at the wages of women relative to men, or when analyzing the wages of ethnic minorities relative to the majority, while the second methodology is exclusively used for analyzing immigrant wages compared to those of natives. However, when analyzing immigrant wages from a policy perspective, it is important to know not only if immigrants catch up eventually, but also why they do not, if that is the case. They may lack formal qualifications, or they may be discriminated against, even when they have spent a long time in the host country. Obviously, the policy implications are widely different.

In this paper we present an extension of the wage decomposition methodology which allows us to decompose observed wage differences of immigrants relative to natives into three different components: qualifications, discrimination and assimilation. Moreover, we apply the methodology to a rich Danish data set in order to present a detailed picture of the anatomy of wage differences between immigrants and natives. To complete this picture, we also present an analysis of gender wage differences within each of the immigrant and native groups considered.

The wages of immigrant men have most often been analyzed using the wage assimilation framework. The general findings are that there are initial wage differences, but that these tend to decline over time, as immigrants spend time in the host country, see e.g. Borjas (1987). Previous 
research on wages of immigrant women in North America finds no unfavorable wage gap due to foreign country of origin. Based on cross-section data, Long (1980, U.S. data), Beach and Worswick (1993, Canadian data) and Shamsuddin (1998, Canadian data) find that the wages of immigrant women are $12-14 \%$ higher than those of native women, conditional on their characteristics. However, Field-Hendrey and Balkan (1991) show that these conclusions are artifacts of the simplified cross-sectional approaches. Using two independent cross-sections, correcting for selectivity and predicting actual work experience, they find a picture similar to the one traditionally found for immigrant males: An initial wage disadvantage and a gradual closing of the gap, see e.g. Borjas (1987).

When analyzing the wage gap between immigrants and natives, the general finding is that there is a wage gap (though often it is not as large as the gender wage gap), some of which is explained by differences in qualifications and some is caused by discrimination or behavioral differences, see e.g. Altonji and Blank (1999). But there is considerable variation in the empirical results obtained from different countries and based on different types of data and econometric models. Altonji and Blank (1999) also note the importance of an adequate econometric model, and they point to the importance of observing (or estimating) actual work experience rather than just education-corrected age (e.g. potential experience) because the ratio of actual to potential experience is likely to vary across ethnic groups and/or gender.

Summing up, there is something to be learnt by performing decomposition analyses on the basis of the wage regressions. On the other hand, assimilation analyses complement the static decomposition methods by focusing on the evolution of the wages of immigrants over time. Moreover, there is evidence that the formulation of the econometric model and the type and quality of data, i.e. cross-section versus panel data, and actual versus potential work experience, are important for obtaining 'correct' estimation results.

Based on a Danish register-based panel data set, which allows us to follow these guidelines, we investigate the native-immigrant wage gap. We estimate wage equations using state-of-the-art panel data sample selection models and extend available wage decomposition techniques to analyze such differences. The estimations enable us to decompose the differences between immigrant and native wages into three components: a qualifications component, a discrimination component and an assimilation component. 
Trying to identify the effect of assimilation, it is particularly important to measure actual work experience rather than just potential experience. Availability of actual work experience allows us to distinguish the returns to work experience obtained in the host country from the returns to just spending time in the host country. In addition to solving the problem of the inaccuracy of potential experience, this enables us to disentangle the differences in assimilation from discrimination of immigrants.

A related problem which also prevails for groups with low participation rates, is the possible sample selection due to the participation decision. The proposed estimator alleviates these problems by allowing for sample selection on observed and unobserved variables (and on both random effects and on the idiosyncratic error term).

Our main finding is that there are significant immigrant (and gender) wage gaps to be explored. Performing traditional static wage decompositions, we find that the gender wage gaps are dominated by the discrimination component, whereas the wage gaps of immigrants relative to natives are mainly caused by differences in qualifications. When we perform the extended analysis of immigrant wage differences, we find that if it were not for the assimilation component, the wage gap would be much larger. Especially for male immigrants the assimilation effect is large. On the other hand, we also find that the major reason for the continued presence of severe wage gaps is a lack of employment assimilation. If only immigrants had worked during all (or most of) the time spent in Denmark (and hence accumulated work experience in Denmark), the wage gap would be much smaller. We calculate the immigrant wage gap in the hypothetical state of 'perfect assimilation' in which immigrants are assumed to have been fully employed in the host country for a ten-year period. In the 'perfectly assimilated state', an immigrant wage gap would remain for some groups. For males, the gap remains due to low formal qualifications in terms of education, work experience and occupational status, whereas for women it remains due to low remuneration of formal qualifications, that is, discrimination. Hence, the extended analysis provides new insights and - to some extent - changes the conclusions obtained from the traditional static analysis.

The paper is organized as follows: Section 2 gives a theoretical background. Section 3 describes the estimation method applied as well as the extended wage decomposition technique. Section 4 presents the data sets used and section 5 discusses the determinants of wages for natives and for 
female and male immigrants from different countries of origin. Section 6 presents the results from decomposition analyses and section 7 concludes the study.

\section{Theoretical background}

There may be given many explanations of wage differentials between natives and immigrants. From the literature on immigration, the theories of assimilation claim that over time the wages of immigrants tend to converge towards those of natives, due to the acquisition of language proficiency, cultural qualifications and more general human capital qualifications, see e.g. the classical article by Chiswick (1978). This assimilation process reduces the earnings gap between immigrants and natives until the human capital of immigrants eventually approaches that of natives. If there is discrimination, the wage gap would not be closed completely between natives and assimilated immigrants (Lalonde and Topel, 1997).

The assimilation theory argues that immigrants, when they arrive in the new host country, are typically less productive - conditional on their level of education and experience etc. - than their native counterparts. Therefore, when analyzing immigrant wage gaps in the presence of potential discrimination, it is important to disentangle the assimilation effect from a potential discrimination effect due to ethnicity. This holds especially in 'new immigrant countries' like many European countries, including Denmark, where most of the immigrants have arrived recently.

Besides the assimilation theories, there may of course also be room for traditional discrimination theory as an explanation for why immigrants earn less than their productive capacity would predict. Numerous theories attempt to explain the existence of wage differences between seemingly equally productive types of workers.

The first group of theories is the classical Beckerian taste based discrimination theories where employers, employees or consumers have preferences against some groups of immigrants or women. Therefore, some firms pay lower wages to immigrants (or women). A general result from these theories is that wage differentials will disappear in the long run due to competition or segregation, though the introduction of imperfect information or search moderate this conclusion (Altonji and Blank, 1999). 
A second group of theories explain wage differentials by the existence of information asymmetries and statistical discrimination. If the employers have less information about the skills and turnover propensity of immigrant applicants from a certain ethnic group, or of a young female applicant, compared to native males, this may induce employers to discriminate in a statistical sense. The classical theory on statistical discrimination by Phelps (1972) does not explain why some groups on average earn less than their productive capacity, since statistical discrimination only harms individuals who have an above average productivity while less productive workers are overcompensated. However, if firms are risk-averse, the uncertainty about immigrants or females may be seen as a cost for the firm, and this may explain why these groups earn lower wages on average. ${ }^{1}$ As an example, employers may have old and outdated information which tends to understate the productivity of the minority group.

More recent theories of the statistical discrimination tradition (e.g. Coate and Loury, 1993) argue that statistical discrimination against a certain ethnic group (or women) may induce employers to allocate workers from that ethnic group into jobs with a lower level of on-the-job-training. Thus, even though the initial skills for the ethnic group and the majority group were on average identical, statistical discrimination may end up being self-fulfilling, i.e. the ethnic minority group may end up with lower skills than the majority group.

A third group of explanations of gender or ethnic group wage differentials are theories of labor market segmentation caused by, e.g. the type of education chosen. If women or immigrants tend to choose educations leading to occupations with low wages or low wage dispersion, then this segmentation will lead to observed aggregate wage gaps. Whether wage differences between occupational categories reflect unobserved differences in e.g. job characteristics or are themselves the result of discriminatory forces is a well-known, though controversial, question, see e.g. Cain (1986).

In addition, there is systemic discrimination, that is, wage differences caused by labor market dynamics and frictions. Suppose that wage dispersion exists among equally qualified workers due to search or other labor market frictions, see Burdett and Mortensen (1998). It may be the case that immigrants and natives have different job offer arrival rates, either due to differences in

\footnotetext{
${ }^{1}$ Alternatively, the higher uncertainty about the qualifications of minority groups may imply a lower return to job matching between employer and employees, which may also explain lower wages for minority groups, see Oettinger (1996).
} 
search channels applied or due to behavioral differences. In addition, immigrants and natives may have different quit and/or firing rates. In these cases, immigrants and natives are likely to 'climb the wage ladder' at different speeds, and therefore they have different average wages, even if they draw job offers from the same wage distribution. Bowlus (1997) analyses gender wage gaps along these lines.

All in all, there are various potential explanations of wage differentials between men and women and between immigrants and native born individuals. The purpose of the present paper is to identify three of these sources of wage differences, namely assimilation, discrimination and differences in qualifications.

\section{Methodology}

Let $y^{e}$ denote the dependent variable, the log of hourly wages, for individuals of ethnicity $e$ ( $n$ for natives and $i$ for immigrants), for those who have an observed wage. Let $x^{e}$ denote the explanatory variables used for ethnicity $e$. Our interest is in the coefficients of the equations

$$
\begin{aligned}
& y^{n}=x^{n} \beta_{n}+\varepsilon^{n} \\
& y^{i}=x^{i} \beta_{i}+\varepsilon^{i}
\end{aligned}
$$

The number of explanatory variables will be larger for immigrants than for natives. Specifically, for immigrants we include a variable measuring how long the individual has spent in the immigration country, usually denoted years since migration. The coefficient on this variable is the one typically used to identify economic assimilation. In addition to this, we are interested in the added effect of obtaining employment and thus accumulating work experience in the host country. This complicates the decomposition analysis of wage differences somewhat, but we will return to this after the derivation of the likelihood function for estimating the equations above.

The availability of a panel data set instead of a single cross section allows us to distinguish age, experience and cohort effects from the assimilation process. ${ }^{2}$ In addition, if not controlled for, severe sample selection bias may be expected, since employment rates vary considerably across gender and ethnicity. Therefore, the appropriate estimator is one that exploits the panel aspect of the data and corrects for sample selection bias. This may be done in various ways. Jensen et al. (2001) survey different panel selection estimators and advocate using a particular random effects

\footnotetext{
${ }^{2}$ See Borjas (1987) and LaLonde and Topel (1997).
} 
estimator, when the equation of interest is mainly the wage equation. ${ }^{3}$ In the following, we briefly describe this estimator.

For a given sub-sample, the model consists of a wage equation and a selection equation. For individual $i$ in time period $t$, the model is the following, employing a standard latent variables specification:

$$
\begin{aligned}
& y_{i t}^{*}=x_{i t} \beta+\alpha_{i}+\varepsilon_{i t} \\
& d_{i t}^{*}=z_{i t} \gamma+\eta_{i}+v_{i t} \\
& d_{i t}= \begin{cases}1 & \text { if } d_{i t}^{*}>0, \\
0 & \text { otherwise }\end{cases} \\
& y_{i t}=y_{i t}^{*} \cdot d_{i t}
\end{aligned}
$$

where $d_{i t}$ is an indicator for having an observed wage, $y_{i t}$ denotes log wage, $x_{i t}$ and $z_{i t}$ are vectors of explanatory variables, and $\alpha_{i}, \eta_{i}$ are individual-specific random effects. We assume that $\boldsymbol{k}_{i t}, v_{i t}(\sim \mathrm{N}(0,0, \Sigma)$, where

(2) $\Sigma=\left[\begin{array}{cc}\sigma_{\varepsilon} & \rho \sigma_{\varepsilon} \\ \rho \sigma_{\varepsilon} & 1\end{array}\right]$

The bivariate random effects are assumed to follow a discrete distribution with $2 \times 2$ points of support, and we assume independence between idiosyncratic error terms and random effects; $\varepsilon_{i t}, v_{i t} \perp \alpha_{i}, \eta_{i}$.

Let $\alpha=\left\{\alpha_{1}, \alpha_{2}\right\}, \eta=\left\{\eta_{1}, \eta_{2}\right\}$ and $p=\left\{p_{11}, p_{12}, p_{21}, p_{22}\right\}$, where $p_{k j}=\operatorname{Pr}\left(\eta_{k}, \alpha_{j}\right)$, and let $\psi=\left[\beta, \gamma, \sigma_{\varepsilon}, \rho, p, \alpha, \eta\right]$ denote the parameter vector. The following expression is the contribution to the likelihood function for a single individual

$$
\begin{aligned}
L_{i}(\psi) & =\iint \prod_{t=1}^{T_{i}} f\left(\varepsilon_{i t}, v_{i t} \mid x_{i t}, z_{i t}, \eta_{i}, \alpha_{i}\right) d G\left(\eta_{i}, \alpha_{i}\right) \\
& =\sum_{j=1}^{2} \sum_{k=1}^{2} p_{k j} \prod_{t=1}^{T_{i}} f\left(\varepsilon_{i t}, v_{i t} \mid x_{i t}, z_{i t}, \eta_{k}, \alpha_{j}\right)
\end{aligned}
$$

where $G(. .$.$) is the joint \mathrm{CDF}$ of the random effects, and

\footnotetext{
${ }^{3}$ Consult Vella (1998) and Jensen et al. (2001) for surveys of these models, and see Vella and Verbeek (1999) or Dustmann and Rocchina-Barrachina (2000) for empirical examples of panel selection estimators. See Husted et al. (2001) for more details about the estimation technique used in this paper and for comparisons to simpler estimators.
} 


$$
\begin{gathered}
f\left(\varepsilon_{i t}, v_{i t} \mid x_{i t}, z_{i p} \alpha_{i}, \eta_{i}\right)=\Phi_{v}\left(-z_{i t} \gamma-\eta_{i}\right)^{1-d_{i t}} \\
{\left[\left(1-F_{\mathrm{v} \mid \varepsilon}\left(-z_{i t} \gamma-\eta_{i} \mid y_{i t}-x_{i t} \beta-\alpha_{i}\right)\right) \cdot f_{\varepsilon}\left(y_{i t}-x_{i t} \beta-\alpha_{i}\right)\right]^{d_{i t}}}
\end{gathered}
$$

where $f(),. F($.$) are used as generic expressions for the normal densities and distribution functions$ for the variables indicated by subscripts, and $\Phi($.$) is a standard normal distribution function.$

The model is estimated for native males $(n m)$ and females $(n f)$, and five different groups of immigrants of each gender (im, if). Using formulae to be derived below, the average expected log wage of participants - denoted $\hat{y}^{e g}$ for the sample of individuals with ethnicity $e$ and gender $g$ - may be calculated for each sample.

Define the overall gender wage gap within a certain ethnic group $e$ as $\Delta_{\mathrm{G}}$, and decompose it in the spirit of Oaxaca (1973) into two components reflecting differences in qualifications $\left(Q_{G}\right)$ and differences in coefficients $\left(D_{G}\right)$, often denoted the discrimination or unexplained component: ${ }^{4}$

$$
\begin{aligned}
\Delta_{G} & =\hat{y}^{e m}-\hat{y}^{e f} \\
& =\underbrace{\hat{y}^{e m}-\hat{y}^{e f e m}}_{Q_{G}}+\underbrace{\hat{y}^{e f e m}-\hat{y}^{e f}}_{D_{G}}
\end{aligned}
$$

where the superscripts $e g e^{\prime} g$ ' now denote that the average expected log wage is calculated for ethnicity $e$ and gender $g$, using the parameters estimated for individuals of ethnicity $e$ ' and gender $g{ }^{5}$ Analogously, the immigrant wage gap for gender $g$ between natives and immigrants from a given ethnic group is given by:

$$
\Delta_{E}=\underbrace{\hat{y}^{n g}-\hat{y}^{i g n g}}_{Q_{E}}+\underbrace{\hat{y}^{i g n g}-\hat{y}^{i g}}_{D_{E}}
$$

\footnotetext{
${ }^{4}$ We use the notion 'discrimination component', although $D$ may overstate discrimination if there are important unobserved qualification variables (for instance language proficiency) and understate discrimination if we include explanatory variables (for instance occupational level) which are affected by discrimination, see e.g. Altonji and Blank (1999).

5 The alternative decomposition writes $\Delta_{G}=\hat{y}^{e m}-\hat{y}^{\text {emef }}+\hat{y}^{\text {emef }}-\hat{y}^{e f}$. We have performed both decompositions, but here we present only one of them. We do not go into any detail with the decomposition of the expected values of the random effects and idiosyncratic errors. As illustrated by Neuman and Oaxaca (1999), it is debatable whether decomposition of the selectivity terms should be interpreted as stemming from discrimination or qualification.
} 
The specification above represents a traditional Oaxaca decomposition framework. There is, however, an additional complication when it comes to immigrants, namely that some of the wage differences between immigrants and natives are due to the fact that immigrants are not perfectly assimilated. For instance, most studies find that immigrants immediately upon immigration earn considerably less than native born individuals, but that this wage gap tends to decline over time, see e.g. Chiswick (1978) and Borjas (1987). Combining the experience from the 'discrimination literature' with the 'assimilation literature', one may ask how (lack of) assimilation affects the decomposition of immigrant/ethnic wage differences. To see this more clearly, consider the terms in (6) again. $\hat{y}^{\text {igng }}$ measures the average expected log wage of an immigrant, evaluated at the payoff rates (coefficients) of natives for a given gender $g$. However, the estimated parameter vector for natives does not include a parameter for the immigrant-specific variable years since migration (YSM). Hence, in the decomposition above, this is implicitly set to zero. The term $Q$ thus measures differences due to traditional characteristics only, including work experience accumulated in the host country, which may be an integral part of the assimilation process. $D$ captures discrimination in the usual sense as well as wage differences due to a lack of assimilation; immigrants lack some country-specific human capital, which they can only gradually acquire by spending time in the immigration country, that is, by accumulating years since migration (YSM).

In order to identify the effect on the immigrant wage gap of the assimilation process, we define two polar states in this process: The 'unassimilated state' and the 'perfectly assimilated state'.

The unassimilated state for an immigrant is defined as the state as newly arrived immigrant when $Y S M=0$, accumulated work experience in host country Exper=0, and the individual's age is the age at migration $(A A M)$. The unassimilated state can be used as a benchmark against which to measure the amount of assimilation achieved by the actual immigrant population.

As time goes by after migration, YSM increases, the immigrant becomes older and may acquire work experience in the host country. We define the 'perfectly assimilated state' ${ }^{6}$ as a state where $Y S M=10$, Exper $=10$, and Age $=A A M+10$. This state is intended to measure the wage of an immigrant in the best of all possible cases, in terms of employment, that is, the wage in the case

\footnotetext{
${ }^{6}$ Note that by 'perfect assimilation' we do not mean the elimination of wage differences. Rather, the term implies that immigrants' wages are as close to those of natives as they will get.
} 
of perfect assimilation. Of course, this state is hypothetical for most immigrants since they will probably not be able to work full time in the host country from the first day after immigration. It is also somewhat arbitrary to select $Y S M=10$ years, and there may be differences in the speed of the assimilation process between individuals and ethnic groups. However, previous research on the assimilation process for Danish immigrants (Husted et al., 2001) indicates that it is reasonable to assume perfect wage assimilation for an immigrant with 10 years of experience in the host country. The 'perfectly assimilated state' can be used to measure the extent to which observed wage differences could have been eliminated or reduced if the process of integrating immigrants into the labor market worked smoothly.

Now, consider a more elaborate decomposition of the immigrant wage gap, which allows for separate identification of all three components

$$
\begin{aligned}
\Delta_{E} & =\hat{y}^{n g}-\hat{y}^{i g} \\
& =\underbrace{\hat{y}^{n g}-\hat{y}^{i^{*} g n g}}_{Q_{E}^{*}}+\underbrace{\hat{y}^{i^{*} g n g}-\hat{y}^{\hat{*}^{*} g i g}}_{D_{E}}+\underbrace{\hat{y}^{*^{*} g i g}-\hat{y}^{i g}}_{A^{\prime}}
\end{aligned}
$$

Here, the term $\hat{y}^{i * g i g}$ measures the average predicted log wage of a 'standardized' sample of immigrants, $i^{*}$, evaluated at the coefficients of the actual immigrant sample, $i$. The only thing that is changed relative to the observed value $\hat{y}^{i g}$ of the actual sample is that we change the value of YSM, Age and Exper, and we give these variables the value of the hypothetical state (*), where * denotes either the 'unassimilated state' or the 'perfectly assimilated state'. Analogously, the term $\hat{y}^{i * g n g}$ denotes the average predicted log wage of immigrants in state *, evaluated with the coefficients of the natives (note that here the variable years since migration do not enter, so this coefficient is implicitly set to zero in this calculation).

The choice of the hypothetical state ('unassimilated' or 'perfectly assimilated') affects the interpretation of the components in the decomposition of $\Delta_{\mathrm{E}}$ in (7). Consider first the case of the 'unassimilated state'; the first component, $Q_{E}^{*}$, now measures the effect of differences in qualifications (including work experience and age differences) between natives and a (standardized) sample of unassimilated immigrants. Unassimilated immigrants are identical to the actual immigrants in our sample, except for the standardizations $Y S M=$ Exper $=0$ and an age which corresponds to age at migration. The second element, $D_{E}^{*}$, measures the differences in returns to the characteristics of the unassimilated immigrants relative to natives, that is, 
discrimination in our terminology. The third - new - element, $A^{*}$, measures the effect of assimilation, that is, the difference in the wage of the unassimilated sample and the observed sample of immigrants. If this expression is negative, it means that immigrants have gained since arrival, due to (partial) assimilation. ${ }^{7}$

Similarly, in the case of the 'perfectly assimilated state', the first term captures differences in qualification of natives and a standardized sample of immigrants who have been in Denmark, working, for ten years. The second component captures discrimination of the "perfectly assimilated' immigrants. The third term now captures the remaining wage assimilation that the actual group of immigrants may expect (or could have experienced, had they all been working full-time), under the assumption that immigrants who have been in Denmark for 10 years are as well assimilated as possible. The sum $\Delta_{E}^{*}=Q_{E}^{*}+D_{E}^{*}$ indicates the immigrant wage gap that would remain if all immigrants were perfectly assimilated in our sense.

Underlying this decomposition technique is the idea that we want to separate assimilation from qualifications and discrimination, a goal which is not achieved by the traditional decomposition techniques. By employing the present framework, we can standardize the immigrants and analyze wage differences due to qualifications, discrimination and assimilation over the entire assimilation process. As a consequence, there should be some caution in the interpretation of the qualification component, as this is calculated using immigrants who have an artificial endowment of years since migration, work experience and age.

What remains, now, is to derive expressions for the components in (7) for different cohorts using a given set of characteristics and coefficients. In order to do this, we must be able to calculate the average expected log wage. Conditional on participation in a given year and on the entire path of participation indicators, the average expected log wage for an individual is

$$
\begin{aligned}
& E\left[y_{i t} \mid d_{i 1}, \ldots, d_{i t}=1, \ldots, d_{i T_{i}}, x_{i t}, z_{i 1}, \ldots, z_{i T_{i}}\right]=x_{i t} \beta \\
& +E\left(\alpha_{i} \mid d_{i 1}, \ldots, d_{i T_{i}}, z_{i 1}, \ldots, z_{i T_{i}}\right)+E\left(\varepsilon_{i t} \mid d_{t}=1, z_{i t}\right)
\end{aligned}
$$

where we have temporarily suppressed the superscripts for notational convenience. The expected values of the error components of the wage equation are

\footnotetext{
${ }^{7}$ There is of course an alternative decomposition using the immigrant coefficient vector as a basis for comparison. However, in the case of immigrant wage gaps, it seems intuitively obvious to use the coefficient vector of the majority group as a basis for comparison.
} 


$$
\begin{aligned}
& E\left(\alpha_{i} \mid d_{i 1}, \ldots, d_{i T_{i}}, z_{i 1}, \ldots, z_{i T_{i}}\right)=\sum_{j=1}^{2} \alpha_{j} q_{j i}^{\alpha} \\
& E\left(\varepsilon_{i t} \mid d_{i t}=1, z_{i t}\right)=\rho \sigma_{\varepsilon} \sum_{k=1}^{2} q_{k i t}^{\eta} \frac{\phi\left(z_{i t} \gamma+\eta_{k}\right)}{\Phi\left(z_{i i} \gamma+\eta_{k}\right)}
\end{aligned}
$$

The term $q_{j i}^{\alpha}$ denotes the individual specific probabilities of $\alpha_{i}$. It is given by:

$$
q_{j i}^{\alpha}=\frac{\sum_{k=1}^{2} p_{k j} \prod_{t=1}^{T_{i}}\left[\Phi\left(z_{i t} \gamma+\eta_{k}\right)\right]^{d_{i t}}\left[1-\Phi\left(z_{i t} \gamma+\eta_{k}\right)\right]^{1-d_{i t}}}{\sum_{l=1}^{2}\left[\left(p_{l 1}+p_{l 2}\right) \prod_{t=1}^{T_{i}}\left[\Phi\left(z_{i t} \gamma+\eta_{l}\right)\right]^{d_{i t}}\left[1-\Phi\left(z_{i t} \gamma+\eta_{l}\right)\right]^{1-d_{i t}}\right]}
$$

and $q_{k i t}^{\eta}$ denote parameters of the individual-time specific probability of $\eta_{i}$ :

$$
q_{k i t}^{\eta}=\frac{\sum_{j=1}^{2} p_{k j} \Phi\left(z_{i t} \gamma+\eta_{k}\right)}{\sum_{j=1}^{2}\left[p_{1 j} \Phi\left(z_{i t} \gamma+\eta_{1}\right)+p_{2 j} \Phi\left(z_{i t} \gamma+\eta_{2}\right)\right]}
$$

Reintroducing superscripts, the average expected log wage across all individuals and all years where these individuals are observed to be working, is thus

$$
\hat{y}^{e g}=\frac{\sum_{i=1}^{I^{e g}} \sum_{t=1}^{T_{i}} d_{i t} E\left[y_{i t} \mid d_{i 1}, \ldots, d_{i T_{i}}, z_{i 1}, \ldots, z_{i T_{i}}, x_{i t} ; \psi^{e g}\right]}{\sum_{i=1}^{I} \sum_{t=1}^{T_{i}} d_{i t}}
$$

where $I^{e g}$ denotes the number of individuals in the sub-sample, and $T_{i}$ the number of observations for a given individual. The terms entering equation (5)-(7) are calculated using equation (9). Hence, the expected value for ethnicity $e$ and gender $g$ evaluated at the estimated coefficients for ethnicity $e^{\prime}$ and gender $g$ ' is the following:

$$
\hat{y}^{\text {egég }}=\sum_{i=1}^{I^{e g}} \sum_{t=1}^{T_{i}} \frac{d_{i t} E\left(y_{i t} \mid d_{i 1}, \ldots, d_{T_{i}}, z_{i 1}, \ldots, z_{i T_{i}}, x_{i t}, \psi^{e^{\prime} g^{\prime}}\right)}{\sum_{i=1}^{I} \sum_{t=1}^{T_{i}} d_{i t}}
$$

where $e, e^{\prime}=n, i$ and $g, g^{\prime}=m, f$. We assume that the expected values of the unobserved variables in the wage equation reflect meaningful unobserved characteristics of the individuals. In the case of $\alpha_{i}$ that might include intelligence and/or human capital from the country of origin and in the case 
of $\varepsilon_{i t}$, it might include motivation or luck. As a consequence of this interpretation, the predicted error components of the wage equation are unaffected by changing the endowment of YSM, Exper and age in the two hypothetical states. Hence, once we have calculated the expected values of $\alpha_{i}, \varepsilon_{i t}$, we treat these as known when calculating expected wages for the 'standardized' samples.

\section{Data description}

\subsection{Immigration to Denmark}

Although Denmark does not have a large population of immigrants, this population has grown at considerable speed since 1980, where first generation immigrants made up $2.7 \%$ of the population. By 2000 the fraction reached 5.6\% corresponding to approximately 300,000 individuals. In the 1960s and early 1970s, the dominant part of immigrants to Denmark were labor migrants and tied movers, mainly from Turkey, Pakistan and the former Yugoslavia. Immigrants from the other Nordic countries (Sweden, Norway, Finland and Iceland) made up another large group. Immigration of 'guest workers' was stopped by law in 1973, while refugee immigration grew rapidly, especially after the mid 1980s. Throughout the period, there have been large inflows of tied movers.

\subsection{The sample}

In the empirical analysis we use two register-based data sets. One data set consists of $10 \%$ of the native Danish population (approximately 500,000 individuals) followed during the period 19841995. The other data set contains information about the entire population of immigrants in Denmark (approximately 250,000 individuals in 1995) followed during the same period. The samples are unbalanced, that is, individuals who enter Denmark (or are born) during this period are also in the data sets. The data sets contain information on a large number of demographic and labor market characteristics of the individuals and their families.

In the empirical analysis in the following section, we do not use the total available data sets. Both data sets are restricted to individuals aged 20-59 years in order to reduce selection problems due to retirement and schooling. Furthermore, the sample of Danes is large, hence, we randomly select a sub-sample making up $0.3 \%$ of the entire population in that age category. 
The immigrant sample is restricted to include only first generation non-refugee immigrants. A first generation immigrant is defined as an individual

1) who was born outside Denmark, and

2) who has foreign-born parents or parents with foreign citizenship. If information on one of the parents is missing - which would be the case if the parent is not in Denmark or is dead - but the other parent fulfills the criteria, the individual is also defined as an immigrant. If there is no information on any of the parents then the individual is defined as a first generation immigrant (if he or she is born outside Denmark).

A first generation immigrant usually has a foreign citizenship, but immigrants who have lived in Denmark for a sufficient number of years may have obtained Danish citizenship.

The sample is split into ethnic groups based on the country of origin, and the grouping supposedly reflects cultural and geographical proximity. Grouping by country of origin and by reason for migration is a non-parametric way of reducing cohort effects, and it thus facilitates identification of the assimilation process. ${ }^{8}$ We select five large immigrant groups among the nonrefugee immigrants: Nordic (Swedish, Norwegian, Icelandic and Finnish), Turkish, African, Pakistani and the combined group of immigrants from India \& Sri-Lanka.

\subsection{The dependent variables}

The dependent variables are an employment indicator and the hourly wage rate. The hourly wage is measured in DKK and is deflated by the consumer price index (1995-prices). The information on wages is based on annual earnings divided by a calculated measure of annual hours employed. ${ }^{9}$ Hourly wages are only observed and reliable for individuals who have been employed as wage earners for at least 200 hours during the year.

\footnotetext{
${ }^{8}$ The cohort effect reflects differences in quality across immigrant cohorts. If this quality is correlated with calendar time (i.e. if there is a time trend in the quality of immigrant cohorts), neglect of the cohort effect may lead to biased estimates of the coefficients to years since migration. See Lalonde and Topel (1997) for further details.

${ }^{9}$ Overtime payments and wages in a secondary job are included in the earnings measure. Annual hours, on the other hand, are calculated based on mandatory pension payments. These are proportional to hours worked, but with a maximum payment corresponding to full-time work. Thus, if overtime work and the frequency of secondary jobs vary systematically between immigrants and native-born, we may over- or underestimate the differences between the wage levels of immigrants and native-born individuals.
} 
The employment indicator takes the value 1 if an individual has been working during a given year, and 0 otherwise. In order to be categorized as 'working', a person must have at least 200 working hours during the year. However, working hours and hourly wages are not observed for self-employed individuals and assisting spouses. ${ }^{10}$

Tables A1 and A2 in Appendix A present descriptive statistics for all samples. The hourly wage is higher for men than for women across all ethnic groups, including natives. For both men and women, immigrants from other Nordic countries have the highest wages - even higher than those of native Danes - while immigrants from other ethnic groups have wages that are considerably lower than the wages of native Danes. Immigrants from India \& Sri Lanka have higher wages compared to immigrants from Turkey, Pakistan and Africa.

Employment rates are higher for men than for women, too, except for immigrants from Nordic countries, where women have higher employment rates than men Furthermore, employment rates vary considerably across ethnic origins. They are highest for native Danes, followed by immigrants from Nordic countries, whereas immigrants from Turkey, Pakistan and Africa have remarkably low employment rates. In section 6, we will further investigate whether there is a causal relationship between the low employment rates of these groups (and the implied low levels of work experience) and their low wage rates.

\subsection{The explanatory variables}

The first problem when dealing with wage decompositions is the choice of which variables to include in the regressions. There are arguments for using the 'kitchen sink approach' (throwing into the regression everything and its square, cube, etc.), but there are also arguments for using mainly human capital variables. For instance, when deciding whether or not to include a set of occupational indicators, we are essentially determining whether our measure of discrimination is 'within occupations' or if occupational segregation also 'counts' as discrimination, see e.g. Cain (1986). In this study we have chosen to include broadly defined occupational indicators among the explanatory variables. Hence, our measure of discrimination is within broad occupations.

\footnotetext{
${ }^{10}$ Self-employment is an important economic state for immigrants, since $16 \%$ of the employed immigrants are selfemployed whereas only $8 \%$ of the employed native born are self-employed. However, since we are not able to obtain register information on wages and working hours for the self-employed, they are grouped with the nonparticipants who have no observed wage either.
} 
The total set of explanatory variables used in this study is: age of the individual (and its square), years since migration, indicators for the highest level of formal education obtained in Denmark, years of actual work experience in Denmark, ${ }^{11}$ the aggregate unemployment rate in the year of immigration, a set of occupational indicators and a set of household composition indicators.

Descriptive sample statistics are presented in Tables A1 and A2. On average, the individuals from Turkey, Pakistan and India \& Sri Lanka have been in Denmark for the longest time, although there is not much difference between the various immigrant groups. However, immigrants from Turkey, Pakistan and Africa have the lowest level of actual work experience (in Denmark) relative to the number of years since migration.

The sample contains information only on education acquired in Denmark. Since immigrants who already have a foreign education may quickly acquire formal qualifications corresponding to many years of schooling for Danish-born individuals, we use indicator variables for the highest level of education attained rather than length of schooling. For immigrants the reference category in the estimations is 'no Danish education', while for the group of Danish born it is 'primary education'. On average immigrant women from outside the Nordic countries obtain less education than men Particularly, women from Turkey and Pakistan have the smallest amounts of education.

Since the 1970s, Denmark has experienced very high unemployment, and immigrants have had much higher unemployment rates than native Danes, see Husted et al. (2001). In 1994, the unemployment rate for immigrants from outside EFTA and EU peaked and exceeded $40 \%$. Entering the country in such a year may reduce the probability of finding a job. Generally speaking, if the labor market is tight at the year of entry, it is probably considerably easier to get a job, and this may have long-term effects on the labor market career. Therefore, we include a variable indicating the overall Danish unemployment rate in the year of immigration. For Danish-born individuals the analogue variable is the overall unemployment rate in the year the individual leaves the educational system. The average value of this variable differs between immigrant groups.

\footnotetext{
${ }^{11}$ Actual work experience is calculated on the basis of mandatory pension payments, which are linked to the number of hours worked. It is thus a fairly precise measure, though periods in self-employment and periods as assisting spouse do not add to the accumulated experience. Since many immigrants are self-employed, we expect to be underestimating the actual work experience of immigrants.
} 
A major problem for the analysis is that the registers contain no information on fluency in Danish and the type or length of education and work experience obtained before immigration to Denmark, all of which are expected to be important for the wage potential and the ethnic wage gap. In the econometric analysis, the problem of unobserved pre-immigration characteristics is handled by using a panel data model, where these characteristics are treated as random individual-specific effects. ${ }^{12}$ The random effects estimator is expected to capture time invariant unobserved heterogeneity, but we are not able to control directly for unobserved proficiency in speaking the Danish language which probably varies over time for the individual immigrant. However, we try to capture this assimilation effect by the coefficient on the variables measuring years since migration and work experience. Earlier studies have shown that the experience profile is best modeled using a linear spline, because the often used quadratic form is not sufficiently flexible (Husted et al., 2001). The same approach is used for years since migration. ${ }^{13}$ Household variables describing number of children and age of the youngest child are used to identify the selection equation. These variables are thus not included in the wage equations. For endogeneity considerations the variables describing occupation and experience are only included in the wage equation and not in the selection equation.

\section{Estimation results}

The estimation results are presented in Appendix B. The model is estimated separately for each immigrant group, and for males and females. Tables B1 and B2 show the results from estimation of the selection equation, the wage equation and the distributional parameters.

Concentrating on the wage equation, we find that spending time in Denmark working (accumulating work experience, age and years since migration) increases the wage, at least for the first 5 years in Denmark. After the first 5 years, the experience profile becomes flatter, but in most cases the return stays positive. For natives, the experience profile has the usual concave

\footnotetext{
${ }^{12}$ If the unobserved level of education acquired in the country of origin is correlated with the included explanatory variables, this may result in inconsistent coefficient estimates in the random effects model. An alternative is to use a fixed effects model, such as Kyriazidou (1997), which does not suffer from this problem. We prefer the random effects estimator for efficiency considerations, see Jensen et al. (2001). Furthermore, random effects are intuitively appealing when the observational units are individuals.

${ }^{13}$ We include $Y S M,(Y S M-5) *(Y S M>5),(Y S M-10)^{*}(Y S M>10)$ and similarly for experience.
} 
shape. ${ }^{14}$ Women from Turkey, Pakistan and Africa stand out in the sense that they have by far the flattest experience profiles. Spending time in Denmark without having a job (thus, only accumulating years since migration and age) is generally associated with a declining wage potential, at least during the first 5-10 years in Denmark. The age-wage profile is generally concave, with a maximum around $40-60$ years of age.

The return to education is positive for natives, but in general this is not the case for immigrants. ${ }^{15}$ Particularly, for women from Turkey, Pakistan and Africa, the returns to schooling are negative rather than positive. One possible interpretation of this evidence is that women from these countries who acquire education may, possibly due to discrimination or cultural barriers, find it difficult to obtain a job that matches their qualifications, hence they end up in subsidized employment and 'relief' jobs, which generally pay low wages.

For all sub-samples, the high-level salaried workers earn higher wages. For male and female immigrants from Turkey, Africa, Pakistan and India \& Sri Lanka, workers in skilled occupations earn less than workers in unskilled occupations. This surprising finding must be seen in the light of the very small fractions of immigrants in skilled occupations.

\section{Decomposition analysis of log wage gaps}

In this section, we first present and discuss the results of the traditional decomposition of wage differences between men and women, immigrants and natives (equations (5) and (6)). The gender wage gap for each of the immigrant groups is included in order to present a complete overview of the wage differences in the Danish labor market. Second, we portray the results from our extension of the wage decomposition for the immigrant groups, allowing for separate inference regarding qualifications, discrimination and assimilation (equation (7)).

Before looking at the more detailed decomposition analyses, it is instructive to look at the overall wage gaps between natives and immigrants, $\Delta_{\mathrm{E}}$, and the gender gap within different immigrant

\footnotetext{
${ }^{14}$ To get an exact picture of wage assimilation, age-experience-assimilation profiles are needed. See Husted et al. (2001) for a detailed analysis of the assimilation profiles for males.

15 This finding lends no support to the hypothesis that immigrants have a higher return to education than natives because the value of the human capital from their country of origin increases when they acquire human capital in the destination country, see Duleep and Regets (1999).
} 
groups, $\Delta_{\mathrm{G}}$. These wage gaps which are calculated as average predicted log wage gaps are presented in Figure 1. ${ }^{16}$

Figure 1 reveals that the gender wage gap is substantial for all ethnic groups. The gender wage gap is largest for native Danes and immigrants from other Nordic countries (21\% and 25\%, respectively) while the smallest gender wage gap is found among Pakistani immigrants (12\%). Considering the male immigrant wage gap (which is relative to native Danish males), Nordic immigrant males earn more than Danish males, and hence this wage gap is negative. ${ }^{17}$ All other immigrant groups are characterized by a positive ethnic wage gap, and the largest predicted wage gaps (22-26\%) are found for immigrants from Turkey, Africa and Pakistan. The female immigrants' wage gap is lower than that of males, ranging from $9 \%$ for female immigrants from India \& Sri Lanka, to $17-18 \%$ for female immigrants from Turkey, Africa and Pakistan. The group of immigrants from other Nordic countries stands out with a wage gap of less than $2 \%$, relative to native women. The figure suggests that immigrant men are in a worse position than immigrant women, because of their larger wage gap. However, noting that there is also a considerable gender wage gap among women, the combined effect of gender and ethnicity puts immigrant women in a position, which is clearly worse than their male counterparts. We also note that, contrary to the findings from the U.S. (Altonji and Blank, 1999), the ethnic or immigrant wage gap is of the same order of magnitude as the gender wage gap, at least for nonNordic immigrants. We now proceed by analyzing the composition of these wage gaps.

Figure 1. Average predicted log-wage gaps between native and immigrant males, and between immigrant males and females, by ethnic origin.

\footnotetext{
${ }^{16}$ We present the predicted gaps, which may deviate slightly from the actual gaps, since we estimate a non-linear model by maximum likelihood.

${ }^{17}$ See Pedersen (1996) and Schröder (1996) for more details on Nordic immigrants and their skills.
} 


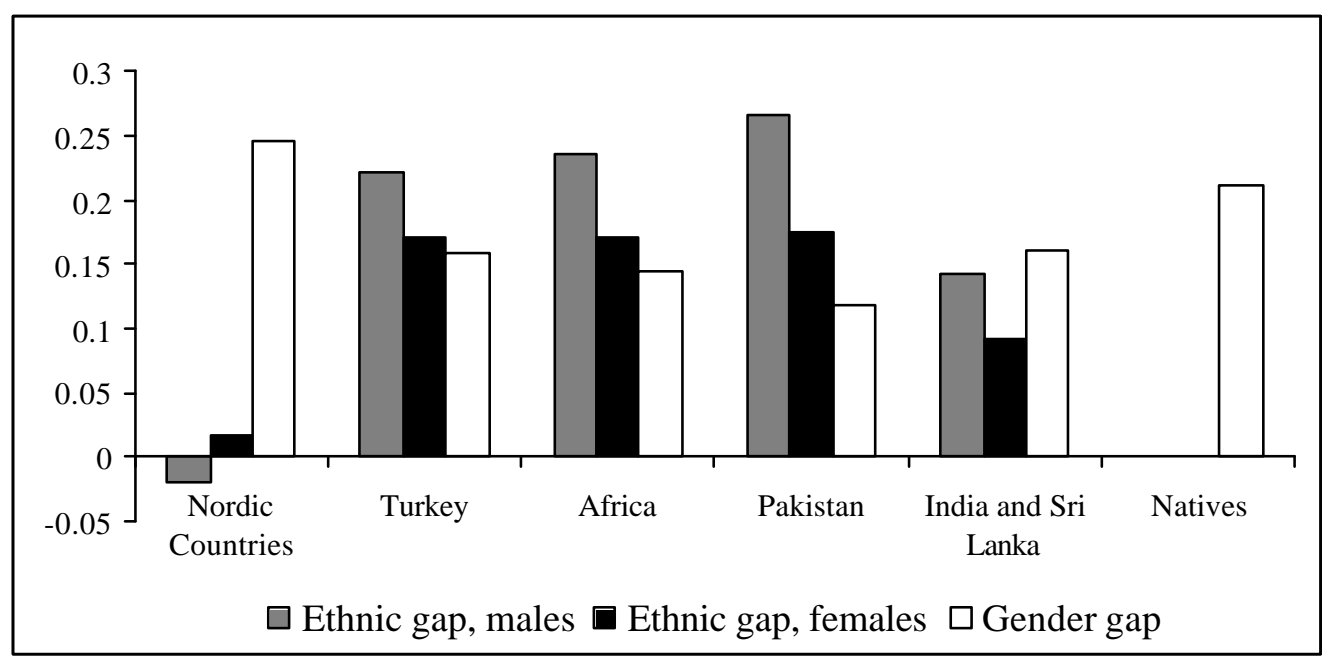

Note: The ethnic and gender wage gaps are defined according to equations (5) and (6).

Table 1 shows decompositions of the gender and immigrant log wage gaps in Figure 1, according to equations (5) and (6), that is, in the traditional way. Concentrating first on the gender wage gap, Table 1 indicates that the dominant part of the gender wage gaps are due to women being remunerated less than men for their observed qualifications, i.e. the gender wage gap is mainly due to the discrimination component, $D_{G}$. It is important to stress that $D_{G}$ may also, besides discriminatory forces, represent differences between male and female immigrants with respect to unobserved productivity or job characteristics. The wage gap due to qualifications between male and female immigrants, $Q_{G}$, is fairly small, although significantly positive, except for Pakistani immigrants, where women seem to have better qualifications than their male counterparts. On the contrary, for native Danes about one third of this difference is due to different qualifications (significant at a $10 \%$ level), while the remainder of the gender wage gap is due to the discrimination component. ${ }^{18}$

Turning to the wage gaps of immigrant men, the log wage gap is significantly positive for all immigrant groups, except for those from the Nordic countries, where it is not significantly different from zero. Looking at the components of the decomposition, we find that for immigrant males from Nordic countries, there is a significant gap (15\%) due to lower qualifications, which is counteracted by negative discrimination $(17 \%)$, henceforth denoted favoritism. For immigrant

\footnotetext{
${ }^{18}$ This result is in accordance with previous studies of the Danish gender wage gap, see e.g. Rosholm and Smith (1996).
} 
men from the four other ethnic groups, the entire wage gap appears to be caused by differences is qualifications, according to Table 1. Especially immigrants from Turkey, Africa and Pakistan have a large qualification gap compared to natives.

Table 1. Decomposition of gender log-wage gaps for natives and five groups of immigrants.

\begin{tabular}{lcccccccccccc}
\hline & \multicolumn{2}{c}{ Natives } & \multicolumn{2}{c}{ Nordic } & \multicolumn{2}{c}{ Turkey } & \multicolumn{2}{c}{ Africa } & \multicolumn{2}{c}{ Pakistan } & \multicolumn{2}{c}{$\begin{array}{c}\text { India \& Sri } \\
\text { Lanka }\end{array}$} \\
\hline & $\begin{array}{c}\text { Contrib } \\
\text { ution }\end{array}$ & $\begin{array}{c}\text { Std. } \\
\text { dev. }\end{array}$ & $\begin{array}{c}\text { Contrib } \\
\text { ution }\end{array}$ & $\begin{array}{c}\text { Std. } \\
\text { dev. }\end{array}$ & $\begin{array}{c}\text { Contrib } \\
\text { ution }\end{array}$ & $\begin{array}{c}\text { Std. } \\
\text { Dev. }\end{array}$ & $\begin{array}{c}\text { Contrib } \\
\text { ution }\end{array}$ & $\begin{array}{c}\text { Std. } \\
\text { dev. }\end{array}$ & $\begin{array}{c}\text { Contrib } \\
\text { ution }\end{array}$ & $\begin{array}{c}\text { Std. } \\
\text { Dev. }\end{array}$ & $\begin{array}{c}\text { Contrib } \\
\text { ution }\end{array}$ & $\begin{array}{c}\text { Std. } \\
\text { dev. }\end{array}$ \\
\hline$Q_{G}$ & $\underline{6.7}$ & 4.0 & $\mathbf{2 . 7}$ & 0.1 & $\mathbf{0 . 6}$ & 0.2 & $\mathbf{0 . 8}$ & 0.2 & $\mathbf{- 3 . 9}$ & 0.3 & $\mathbf{1 . 8}$ & 0.4 \\
$D_{G}$ & $\mathbf{1 4 . 4}$ & 3.6 & $\mathbf{2 2 . 0}$ & 0.6 & $\mathbf{1 5 . 4}$ & 0.4 & $\mathbf{1 3 . 7}$ & 0.8 & $\mathbf{1 5 . 8}$ & 0.8 & $\mathbf{1 4 . 3}$ & 1.6 \\
$\Delta_{G}$ & $\mathbf{2 1 . 1}$ & 4.1 & $\mathbf{2 4 . 7}$ & 0.6 & $\mathbf{1 6 . 0}$ & 0.4 & $\mathbf{1 4 . 5}$ & 0.8 & $\mathbf{1 1 . 9}$ & 0.8 & $\mathbf{1 6 . 1}$ & 1.6 \\
Males & & & & & & & & & & & & \\
$Q_{E}$ & - & - & $\mathbf{1 5 . 1}$ & 1.2 & $\mathbf{2 6 . 4}$ & 5.2 & $\mathbf{2 3 . 0}$ & 5.3 & $\mathbf{2 5 . 8}$ & 8.4 & $\mathbf{1 7 . 9}$ & 1.2 \\
$D_{E}$ & - & - & $\mathbf{- 1 7 . 1}$ & 4.0 & -4.2 & 3.5 & 0.7 & 3.6 & 0.9 & 6.4 & -3.7 & 2.8 \\
$\Delta_{E}$ & - & - & -2.0 & 3.1 & $\mathbf{2 2 . 2}$ & 3.0 & $\mathbf{2 3 . 7}$ & 3.1 & $\mathbf{2 6 . 7}$ & 3.1 & $\mathbf{1 4 . 2}$ & 3.3 \\
Females & & & & & & & & & & & & \\
$Q_{E}$ & - & - & $\mathbf{4 . 2}$ & 1.9 & $\mathbf{1 6 . 3}$ & 2.6 & $\mathbf{1 0 . 8}$ & 2.4 & $\mathbf{1 1 . 1}$ & 2.1 & $\mathbf{7 . 8}$ & 1.2 \\
$D_{E}$ & - & - & -2.5 & 2.2 & 0.8 & 3.4 & $\underline{6.3}$ & 3.6 & $\underline{6.4}$ & 3.6 & 1.5 & 2.7 \\
$\Delta_{E}$ & - & - & 1.7 & 2.7 & $\mathbf{1 7 . 1}$ & 2.7 & $\mathbf{1 7 . 1}$ & 2.8 & $\mathbf{1 7 . 5}$ & 2.8 & $\mathbf{9 . 2}$ & 2.9 \\
\hline
\end{tabular}

Note: Standard errors are computed by the Delta method. Bold coefficients denote statistical significance at a $5 \%$ level, whereas underlined indicates significance at a $10 \%$ level. The ethnic wage gaps refer to males. Decompositions are shown in equations (5) and (6).

Focusing on the wage gaps of immigrant women, it is once again noticed that for Nordic immigrants, there is favoritism rather than discrimination, although the component is not significant. For the remainder of the groups, qualifications explain most or all of the log wage gap to native women. For women from Africa and Pakistan, the discrimination component accounts for about a third of the log wage gap, while for the two other groups, the discrimination component is negligible.

In order to obtain a more detailed picture of the immigrant wage gaps and the assimilation process, we now turn to the decompositions given by (7) which allow us to include the effects of the assimilation process into the traditional decompositions. In Table 2, we show the decompositions for the two hypothetical states described in Section 3, the 'unassimilated state' and the 'perfectly assimilated state'. The decompositions are performed for men and women separately. For the first state, we basically answer the question: 'Suppose the immigrants of ethnicity ' $e$ ' had just arrived to Denmark, found jobs immediately and were paid according to the 
estimated wage equations. How would their wages compare to those of natives, and how do these wages compare to the actual wages of immigrants?'

When interpreting the results in Table 2, one should be aware that the decomposition of log wage gaps in the hypothetical states implies changes in the qualifications and discrimination gaps, too, compared to the numbers in Table 1 . The reason is that individuals from a given ethnic minority in the hypothetical state are endowed with artificial values of Age, YSM and Exper. The sub-total $\Delta_{E}^{*}=Q_{E}^{*}+D_{E}^{*}$ denotes the wage gap that would exist if all immigrants had the hypothetical endowments. As an example, according to Table 2, male immigrants from Nordic countries in the 'unassimilated state' have a $15.3 \%$ log wage gap, caused by a $36.1 \%$ qualifications gap and a $20.8 \%$ favoritism gap. Hence, the (residual) assimilation component is $17.3 \%$. That is, comparing the wage gaps of the hypothetical and the actual samples (15.3\% versus $-2.0 \%)$, assimilation has led to a $17.3 \%$ reduction of the wage gap. Most of this reduction is attributed to improved qualifications and some of it to discrimination, caused by the fact that the discrimination/favoritism component is evaluated at a different level of characteristics.

The overall picture in Table 2 is that the immigrant wage gap is large in the 'unassimilated state' when immigrants have just arrived to the host country. For Pakistani men, the immigrant wage gap in the unassimilated state, $\Delta_{E}^{*}$, is as high as $61 \%$, for Turkish men $42 \%$ and for African, Indian and Sri Lankan men about 36\%. For women from these countries the same figures are $23 \%, 32 \%$ and $21-23 \%$, respectively. Comparing these figures with the calculated immigrant wage gaps in the 'perfectly assimilated state' for males, the values for $\Delta_{E}^{*}$ are reduced considerably for all immigrant groups. Still, a gap would exist, according to the figures in Table 2. For female immigrants, the value of $\Delta_{E}^{*}$ is generally much lower than for males, and so is the reduction in the wage gaps for women when comparing the gaps in the unassimilated state to those in the perfectly assimilated state. 
Table 2. Decomposition of ethnic log wage gaps for five groups of immigrants.

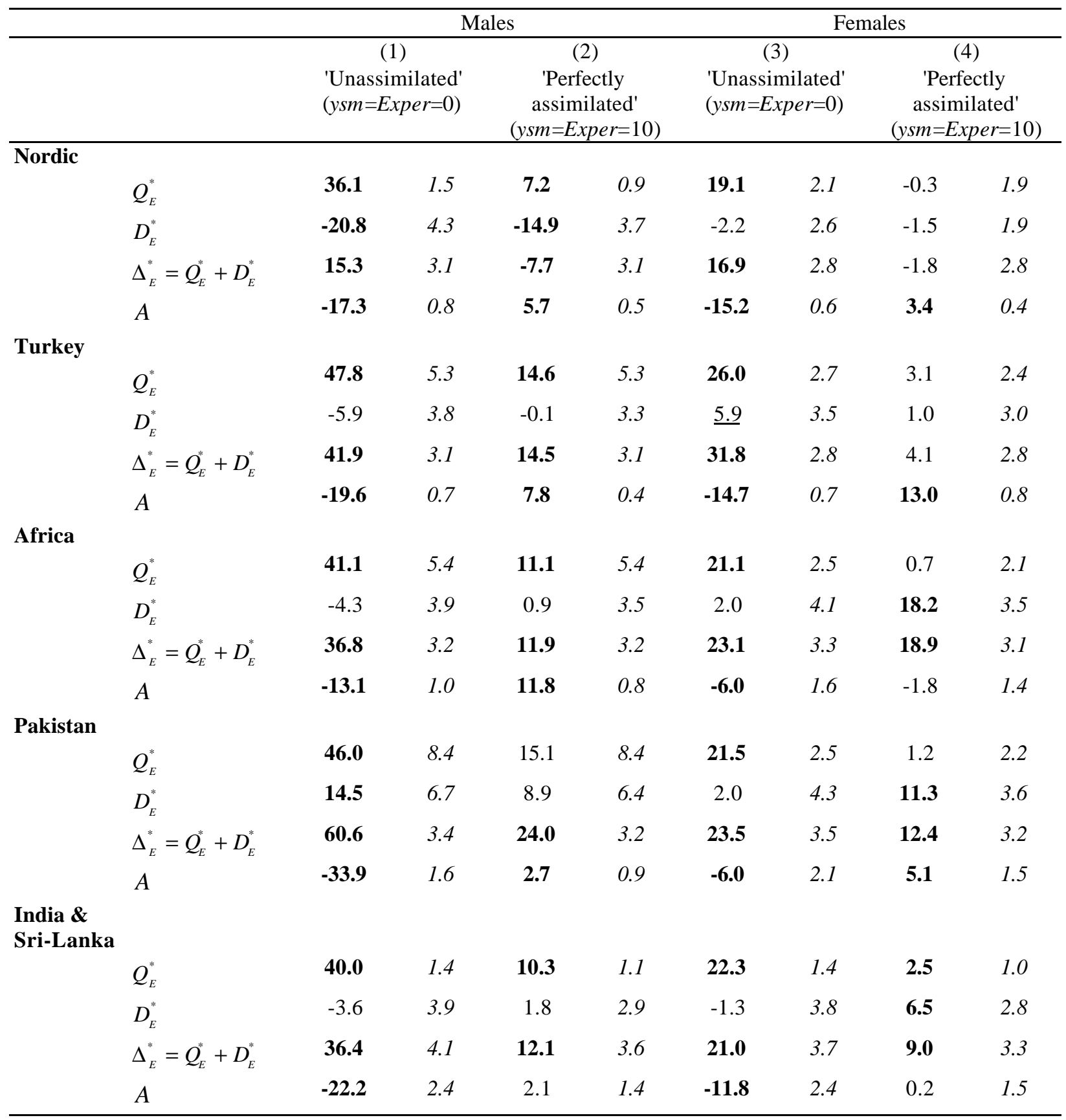

Note: Standard errors are computed by the Delta method. Bold coefficients denote statistical significance at a $5 \%$ level, whereas underlined coefficients indicate significance at a $10 \%$ level. The decomposition is shown in equation (7). Notice that compared to Table 1 , it holds that $\Delta_{E}=\Delta_{E}^{*}+A$.

In accordance with this finding, Table 2 shows that the estimated effect of assimilation, $A$, in Columns 1 and 3 is considerably larger for males than for females. Especially for Pakistani males, the assimilation effect is exceptionally large (34\%), indicating that for this group a strong assimilation process has been going on. However, this group also starts out with the largest wage gap in the unassimilated state. The assimilation effect is much smaller for Turks, Africans and 
immigrants from India \& Sri Lanka. For the latter group it is partly because on average immigrants from India \& Sri Lanka have only been 8 years in Denmark while Turks, Pakistani and Africans have YSM values of on average 10 years (see Appendix, Table A1). The lower female assimilation component indicates that the assimilation process is much weaker for immigrant women than for men (from Non-Nordic countries). Note that these assimilatory gains have been obtained largely by staying in Denmark for 10 years and working only four years, except for the groups of women from Turkey, Pakistan and Africa, who have only been working approximately two years (see the descriptive statistics in Tables A1 and A2).

The discrimination component for 'unassimilated' immigrants is insignificant for all immigrant groups, except for Pakistani men, for whom the discriminatory component is significantly positive and larger upon arrival than later on (see the $D_{E}$ component in Table 1). This finding hinges on the fact that the combined effects of variables other than age, experience and years since migration are more generously rewarded for natives than for Pakistani males.

Columns 2 and 4 show the log ethnic wage gap in the 'perfectly assimilated state'. Note, first of all, that this snapshot is almost equivalent to endowing the actual sample of immigrants with the sample average of YSM and age, the only notable difference thus being the difference in their work experience (the hypothetical values of 10 years against the actual values of 2-4 years for most groups, see Tables A1 and A2). For all groups of immigrants we find that the qualification gap in the perfectly assimilated state is smaller than at the time of arrival. For many groups it is also smaller than its actual value (shown in Table 1), which is not very surprising. As a result, the overall wage gap $\left(\Delta_{E}^{*}\right)$ would have been much smaller if immigrants had been able to work during all their time in Denmark. For Turkish females, the immigrant wage gap would be almost gone, whereas for the other groups of immigrants a considerable wage gap persists. For women from Africa, the overall immigrant wage gap would not change very much. For both African and Pakistani women, the qualification component is reduced but replaced by an increase in the discrimination term, because they get a low remuneration of their qualifications in terms of age, work experience and YSM. Whether this is related to discrimination in the traditional sense, statistical discrimination or unobserved productivity differences (such as for instance preferences for work), is difficult to say.

'In the 'perfectly assimilated state', the wage gaps persist for all male immigrant groups (ignoring Nordic immigrants), and they are exclusively caused by lack of qualifications. For 
women, the persisting wage gaps are exclusively caused by discrimination, a result which is in contrast to those obtained from the traditional decomposition analysis.

\section{Concluding remarks}

In this paper, we analyze immigrant wage gaps and gender wage gaps within immigrant groups in Denmark. In order to do so, we estimate a panel selection model of employment and hourly wages for various groups of non-refugee immigrants and natives. Furthermore, we present and discuss several ways of decomposing wage differences along the ethnic dimension. Especially, we propose a decomposition analysis, which combines two strains of the literature on ethnic/immigrant wage differences, namely the 'discrimination literature' and the 'assimilation literature'. Application of the proposed decomposition techniques provides a rich picture of discrimination and the acquisition of qualifications in the process of assimilation into the labor market of the host country.

Estimation of wage equations for immigrants shows, surprisingly, that in general there is no positive return to obtaining Danish education for immigrants. As usually observed, a wageassimilation process is going on for most immigrant groups.

Large immigrant and gender wage gaps exists and are explored. Traditional decomposition analyses show that while the gender wage gaps within all immigrant groups are dominated by the discrimination component (which may include wage effects from unobserved productivity characteristics), the immigrant wage gap is almost entirely due to differences in qualifications. Individuals from the Nordic countries stand out as they experience the highest gender wage gap and no significant immigrant wage gap at all. With respect to the gender wage gap for Nordic immigrants, it is of a size similar to that among native Danes.

Looking at the results of the extended decomposition, we find that in the 'unassimilated state', where all individuals are endowed with years since migration, age and experience as if they had just arrived, the wage gaps are much larger than their actual value, indicating that some assimilation has been going on. In the 'perfectly assimilated state', which is defined by having been in the country as full-time employed for a 10-year period, a reduced, but still significant immigrant wage gap persists. For male immigrants, it is mainly explained by a qualification component because even 'perfectly assimilated' immigrants have lower formal qualifications in terms of education, experience and occupation. For female immigrants, the gap for perfectly 
assimilated immigrants remains due to a positive discrimination component, a result which is in contrast to that obtained from traditional decompositions. However, the immigrant wage gap in the 'perfectly assimilated state' is much lower than the observed immigrant wage gap because immigrants in general have exceptionally low levels of work experience. For the five immigrant groups analyzed in this study, the average number of years spent in Denmark is 9-11 years, but the average number of years spent in employment is 4-5 years for men and 2 years for women. Thus, although we do not find strong evidence of severe wage discrimination against immigrants, the miserable employment experience of Danish immigrants may be an indication of discriminatory forces in the employment process. However, we leave this important question for future research. Nevertheless, policy implications are fairly clear. Efforts towards reducing the income inequalities between certain immigrant groups and native Danes should not be directed at legislation against wage discrimination, but rather at finding employment for immigrants.

\section{References}

Altonji, J. G. and R. M. Blank (1999), "Race and Gender in the Labor Market", Ch. 48 in Ashenfelter, O. and D. Card (eds.), Handbook of Labor Economics Vol. 3c, North-Holland.

Beach, C. M. and C. Worswick (1993), "Is there a Double-Negative Effect on the Earnings of Immigrant Women?" Canadian Public Policy 19(1): 36-53.

Borjas, G.J. (1987), "Self-Selection and the Earnings of Immigrants." American Economic Review 77(4): 531-553.

Bowlus, A. (1997), “A Search Interpretation of Male-Female Wage Differentials.” Journal of Labor Economics 15(4): 625-657

Burdett, K. and D. Mortensen (1998), "Wage Differentials, Employer Size, and Unemployment.” International Economic Review 39(2): 257-273.

Cain, (1986), “The Economic Analysis of Labour Market Discrimination: A Survey." Ch. 13 in Ashenfelter and Layard (eds.) Handbook of Labour Economics, Vol. 1. North-Holland.

Chiswick, R.B. (1978), “The Effect of Americanization on the Earnings of Foreign-Born Men.” Journal of Political Economy 86(5): 81-87.

Coate, S. and G. Loury (1993), "Will affirmative-action policies eliminate negative stereotypes?" American Economic Review 83 (5), 1220-1240. 
Duleep, H. O. and S. Sanders (1993), "The Decision to Work by Married Immigrant Women.” Industrial and Labor Relations Review 46(4) 677-689.

Dustmann, C., and M. E. Rocchina-Barrachina (2000), "Selection Correction in Panel Data Models: An Application to Labour Supply and Wages.” IZA Discussion Paper 162, Bonn.

Field-Hendrey, E. and E. Balkan (1991), "Earnings and Assimilation of Female Immigrants." Applied Economics 23: 1665-1672.

Husted, L., H. S. Nielsen, M. Rosholm, and N. Smith (2001), "Employment and Wage Assimilation of Male First Generation Immigrants in Denmark." International Journal of Manpower $22(1 / 2)$ 39-68.

Jensen, P., M. Rosholm, and M. Verner (2001), “A Comparison of Different Estimators for Panel Data Sample Selection Models.” Working Paper.

Kyriazidou, E. (1997), 'Estimation of a Panel Data Sample Selection Model.” Econometrica 65 (6) $1335-1364$.

Lalonde, R.J. and R.H. Topel (1997), “The Economic Impact of International Migration and the Economic Performance of Migrants." Ch. 14 in Rosenzweig and Stark (eds.), Handbook in Population and Family Economics. Elsevier Science B. V.

Long, C. (1980), "The Effect of the Americanization on Earnings: Some Evidence for Women.” Journal of Political Economy 88(3): 620-629.

Neuman, S. and R. Oaxaca (1999), "Estimating Labor Market Discrimination with Selectivity Corrected Wage Equation." Working Paper.

Oaxaca, R. (1973), “Male-Female Wage Differentials in Urban Labor Markets.” International Economic Review 14: 693-709.

Oettinger, G. (1996), "Statistical Discrimination and the Early Career Evolution of the BlackWhite Wage Gap", Journal of Labor Economics 14 (1), 52-78.

Pedersen, P.J. (1996), “Aggregate Intra-Nordic and Nordic-EC Mobility.” In E. Wadensjö (ed.), The Nordic Labour Markets in the 1990s, Part II, North Holland.

Phelps, E. S.(1972), “The Statistical Theory of Racism and Sexism, American Economic Review $62,659-661$. 
Rosholm, M. and N. Smith (1996), “The Danish Gender Wage Gap in the 1980s.” Oxford Economic Papers 48: 254-79.

Schröder, L. (1996), "Scandinavian Skill Migration in the 1980s.” In E. Wadensjö (ed.), The Nordic Labour Markets in the 1990s, Part II, North Holland.

Shamsuddin, A. F. (1998), "The Double-Negative Effect on the Earnings of Foreign-Born Females in Canada." Applied Economics 30: 1187-1201.

Vella, F. (1998), "Estimating Models with Sample Selection Bias: A Survey.” Journal of Human Resources 33:127-69.

Vella, F. and M. Verbeek (1999), “Two-step estimation of panel data models with censored endogenous variables and selection bias." Journal of Econometrics 90: 239-263. 


\section{Appendix A. Details about the samples.}

Table A1. Sample means, males.

\begin{tabular}{lcccccc}
\hline & Denmark & Nordic countries & Turkey & Africa & Pakistan & $\begin{array}{c}\text { India } \\
\text { and Sri Lanka }\end{array}$ \\
\hline Wage (DKK) & 157.10 & 175.46 & 128.82 & 132.20 & 127.62 & 146.74 \\
Ln wage (if employed) & 4.99 & 5.03 & 4.80 & 4.80 & 4.78 & 4.89 \\
Employed & 0.73 & 0.49 & 0.45 & 0.42 & 0.38 & 0.50 \\
Primary education & 0.33 & 0.09 & 0.31 & 0.15 & 0.29 & 0.17 \\
Secondary education & 0.03 & 0.03 & 0.01 & 0.02 & 0.03 & 0.03 \\
Vocational education & 0.47 & 0.06 & 0.02 & 0.05 & 0.04 & 0.04 \\
Theoretical education & 0.17 & 0.15 & 0.01 & 0.05 & 0.01 & 0.07 \\
Experience DK & 13.27 & 4.70 & 4.82 & 3.72 & 4.44 & 5.42 \\
Years since migration & - & 8.52 & 10.37 & 8.33 & 10.43 & 10.28 \\
Age & 38.96 & 38.40 & 29.11 & 33.22 & 32.56 & 36.75 \\
Single & 0.31 & 0.44 & 0.23 & 0.38 & 0.38 & 0.31 \\
Youngest child 0-2 yrs & 0.10 & 0.12 & 0.31 & 0.20 & 0.25 & 0.18 \\
Youngest child 3-6 yrs & 0.08 & 0.08 & 0.18 & 0.10 & 0.13 & 0.13 \\
Youngest child 7-17 yrs & 0.22 & 0.13 & 0.18 & 0.12 & 0.16 & 0.20 \\
Number of children & 0.68 & 0.57 & 1.45 & 0.83 & 1.35 & 0.93 \\
High-level salaried & 0.23 & 0.19 & 0.02 & 0.07 & 0.02 & 0.13 \\
Low-level salaried & 0.13 & 0.06 & 0.03 & 0.08 & 0.05 & 0.08 \\
Skilled & 0.19 & 0.05 & 0.03 & 0.05 & 0.03 & 0.05 \\
Missing occupation & 0.18 & 0.53 & 0.51 & 0.57 & 0.53 & 0.43 \\
Unemployment (\%) & 4.99 & 7.46 & 6.80 & 7.56 & 6.50 & 6.55 \\
\hline Sample size & 47,259 & 63,805 & 94,139 & 40,552 & 34,265 & 7,333 \\
\hline
\end{tabular}


Table A2. Sample means, females.

\begin{tabular}{lcccccc}
\hline & Denmark & Nordic countries & Turkey & Africa & Pakistan & $\begin{array}{c}\text { India \& Sri } \\
\text { Lanka }\end{array}$ \\
\hline Wage (DKK) & 122.63 & 128.87 & 108.63 & 112.40 & 112.25 & 117.59 \\
Ln wage (if employed) & 4.76 & 4.78 & 4.64 & 4.66 & 4.66 & 4.72 \\
Employed & 0.68 & 0.52 & 0.23 & 0.28 & 0.19 & 0.43 \\
Primary education & 0.44 & 0.13 & 0.17 & 0.15 & 0.14 & 0.13 \\
Secondary education & 0.03 & 0.04 & 0.01 & 0.02 & 0.02 & 0.03 \\
Vocational education & 0.34 & 0.06 & 0.01 & 0.03 & 0.02 & 0.05 \\
Theoretical education & 0.19 & 0.13 & 0.00 & 0.03 & 0.00 & 0.04 \\
Experience DK & 9.49 & 4.57 & 2.36 & 2.22 & 2.19 & 4.28 \\
Years since migration & - & 9.47 & 9.62 & 8.64 & 10.64 & 11.02 \\
Age & 38.91 & 36.90 & 30.50 & 32.35 & 32.67 & 35.60 \\
Single & 0.26 & 0.35 & 0.13 & 0.26 & 0.16 & 0.20 \\
Youngest child 0-2 yrs & 0.11 & 0.15 & 0.32 & 0.29 & 0.30 & 0.19 \\
Youngest child 3-6 yrs & 0.10 & 0.13 & 0.21 & 0.17 & 0.20 & 0.17 \\
Youngest child 7-17 yrs & 0.26 & 0.22 & 0.24 & 0.20 & 0.27 & 0.31 \\
Number of children & 0.78 & 0.85 & 1.73 & 1.55 & 2.07 & 1.24 \\
High-level salaried & 0.17 & 0.17 & 0.01 & 0.04 & 0.02 & 0.06 \\
Low-level salaried & 0.30 & 0.17 & 0.02 & 0.06 & 0.04 & 0.11 \\
Skilled & 0.01 & 0.01 & 0.01 & 0.01 & 0.00 & 0.02 \\
Missing occupation & 0.28 & 0.49 & 0.75 & 0.72 & 0.77 & 0.54 \\
Unemployment (\%) & 5.07 & 6.98 & 7.13 & 7.49 & 6.39 & 6.34 \\
\hline Sample size & 45,308 & 83,480 & 91,903 & 27,758 & 33,425 & 7,801 \\
\hline
\end{tabular}




\section{Appendix B. Estimation results.}

Table B1. Results from estimation of selection equation.

\begin{tabular}{|c|c|c|c|c|c|c|c|c|c|c|c|c|}
\hline & \multicolumn{2}{|c|}{ Denmark } & \multicolumn{2}{|c|}{ Nordic countries } & \multicolumn{2}{|c|}{ Turkey } & \multicolumn{2}{|c|}{ Africa } & \multicolumn{2}{|c|}{ Pakistan } & \multicolumn{2}{|c|}{ India \& Sri Lanka } \\
\hline & Males & Females & Males & Females & Males & Females & Males & Females & Males & Females & Males & Females \\
\hline \multirow[t]{2}{*}{ Constant 1} & -0.723 & -1.696 & -3.640 & -3.369 & 0.519 & 0.066 & -0.278 & -1.905 & -0.796 & -1.002 & -1.342 & -1.984 \\
\hline & $(0.125)$ & $(0.119)$ & $(0.066)$ & $(0.059)$ & $(0.041)$ & $(0.025)$ & $(0.075)$ & $(0.097)$ & $(0.073)$ & $(0.112)$ & $(0.182)$ & $(0.184)$ \\
\hline \multirow{2}{*}{ Constant 2} & 1.557 & 0.365 & -1.574 & 1.475 & 1.813 & 1.135 & 1.229 & -0.484 & 0.501 & 0.281 & 0.393 & -0.438 \\
\hline & $(0.124)$ & $(0.119)$ & $(0.064)$ & $(0.058)$ & $(0.042)$ & $(0.027)$ & $(0.077)$ & $(0.098)$ & $(0.074)$ & $(0.114)$ & $(0.184)$ & $(0.185)$ \\
\hline \multirow[t]{2}{*}{ Primary education } & & & -0.074 & -0.101 & 0.016 & 0.135 & -0.124 & 0.165 & 0.028 & -0.003 & -0.175 & 0.040 \\
\hline & & & $(0.019)$ & $(0.014)$ & $(0.012)$ & $(0.016)$ & $(0.021)$ & $(0.029)$ & $(0.019)$ & $(0.034)$ & $(0.046)$ & $(0.051)$ \\
\hline \multirow[t]{2}{*}{ Secondary education } & -0.217 & -0.074 & -0.041 & 0.036 & -0.004 & 0.331 & -0.078 & 0.413 & 0.084 & 0.293 & -0.052 & 0.408 \\
\hline & $(0.044)$ & $(0.034)$ & $(0.030)$ & $(0.023)$ & $(0.036)$ & $(0.041)$ & $(0.042)$ & $(0.046)$ & $(0.037)$ & $(0.059)$ & $(0.086)$ & $(0.092)$ \\
\hline \multirow[t]{2}{*}{ Vocational education } & 0.324 & 0.320 & 0.174 & 0.287 & -0.064 & 0.439 & 0.028 & 0.586 & 0.194 & 0.022 & 0.208 & 0.455 \\
\hline & $(0.014)$ & $(0.015)$ & $(0.021)$ & $(0.020)$ & $(0.026)$ & $(0.039)$ & $(0.029)$ & $(0.040)$ & $(0.036)$ & $(0.053)$ & $(0.077)$ & $(0.085)$ \\
\hline \multirow[t]{2}{*}{ Theoretical education } & 0.594 & 0.631 & 0.256 & 0.386 & 0.703 & 0.874 & 0.464 & 0.792 & 0.652 & 1.316 & 0.467 & 0.615 \\
\hline & $(0.020)$ & $(0.019)$ & $(0.015)$ & $(0.013)$ & $(0.032)$ & $(0.054)$ & $(0.028)$ & $(0.051)$ & $(0.060)$ & $(0.128)$ & $(0.057)$ & $(0.080)$ \\
\hline \multicolumn{3}{|l|}{ Years since migration } & 2.727 & 4.254 & -6.074 & 0.776 & 0.144 & 6.603 & -8.719 & 1.402 & -1.511 & 0.983 \\
\hline \multicolumn{3}{|l|}{$/ 100$} & $(0.584)$ & $(0.501)$ & $(0.382)$ & $(0.401)$ & $(0.601)$ & $(0.891)$ & $(0.812)$ & $(0.940)$ & $(1.753)$ & $(1.896)$ \\
\hline \multicolumn{3}{|l|}{ Yrs since migr $(5+y r s)$} & -2.302 & -4.492 & 2.952 & -2.221 & -0.103 & -6.144 & 4.596 & -0.090 & -5.027 & 4.309 \\
\hline \multicolumn{3}{|l|}{$/ 100$} & $(0.883)$ & $(0.734)$ & $(0.535)$ & $(0.677)$ & $(0.916)$ & $(1.326)$ & $(1.151)$ & $(1.142)$ & $(2.636)$ & $(2.613)$ \\
\hline \multicolumn{3}{|l|}{ Yrs since migr $(10+y r s)$} & -3.161 & -0.525 & -3.340 & -2.538 & -0.232 & -4.995 & -2.496 & -2.108 & 3.120 & -7.266 \\
\hline \multicolumn{3}{|l|}{$/ 100$} & $(0.580)$ & $(0.462)$ & $(0.338)$ & $(0.429)$ & $(0.647)$ & $(0.831)$ & $(0.635)$ & $(0.707)$ & $(1.492)$ & $(1.461)$ \\
\hline \multicolumn{3}{|l|}{ Yrs since migr $(20+y r s)$} & 3.613 & -1.400 & 1.708 & & -0.153 & -1.312 & 3.393 & -0.583 & 3.308 & -12.113 \\
\hline \multicolumn{3}{|l|}{$/ 100$} & $(1.464)$ & (1.087) & $(0.359)$ & & $(1.423)$ & $(1.828)$ & $(1.131)$ & $(1.485)$ & $(3.165)$ & $(3.069)$ \\
\hline \multirow[t]{2}{*}{ Unemployment } & 4.107 & -2.137 & -5.159 & -4.184 & -10.538 & -10.140 & -2.016 & -6.178 & -10.550 & -5.858 & -8.644 & -5.068 \\
\hline & $(0.310)$ & $(0.232)$ & $(0.265)$ & $(0.211)$ & $(0.204)$ & $(0.244)$ & $(0.297)$ & $(0.435)$ & $(0.323)$ & $(0.386)$ & $(0.745)$ & $(0.707)$ \\
\hline \multirow[t]{2}{*}{ Single } & -0.292 & -0.142 & -0.178 & -0.101 & 0.010 & 0.111 & -0.091 & -0.006 & 0.087 & 0.298 & -0.011 & -0.144 \\
\hline & $(0.017)$ & $(0.015)$ & $(0.013)$ & $(0.010)$ & $(0.011)$ & $(0.014)$ & $(0.015)$ & $(0.020)$ & $(0.017)$ & $(0.024)$ & $(0.041)$ & $(0.042)$ \\
\hline \multirow[t]{2}{*}{ Age/100 } & 2.668 & 8.662 & 16.304 & 15.795 & 2.786 & 1.241 & -0.055 & 7.282 & 8.441 & 0.295 & 9.879 & 10.246 \\
\hline & $(0.601)$ & $(0.580)$ & $(0.313)$ & $(0.301)$ & $(0.258)$ & $(0.199)$ & $(0.408)$ & $(0.551)$ & $(0.355)$ & $(0.647)$ & $(0.933)$ & $(1.063)$ \\
\hline Age squared/10000 & -7.501 & -14.125 & -21.377 & -22.016 & -7.002 & -6.340 & -2.583 & -11.969 & -12.400 & -2.757 & -15.241 & -16.338 \\
\hline & $(0.738)$ & $(0.715)$ & $(0.382)$ & $(0.378)$ & $(0.378)$ & $(0.300)$ & $(0.563)$ & $(0.738)$ & $(0.471)$ & $(0.907)$ & $(1.207)$ & $(1.495)$ \\
\hline Youngest child $0-2$ yrs & 0.303 & -0.377 & 0.249 & -0.143 & 0.091 & -0.011 & 0.129 & -0.047 & 0.192 & 0.010 & 0.109 & -0.151 \\
\hline & $(0.037)$ & $(0.032)$ & $(0.027)$ & $(0.019)$ & $(0.012)$ & $(0.011)$ & $(0.021)$ & $(0.024)$ & $(0.020)$ & $(0.025)$ & $(0.059)$ & $(0.063)$ \\
\hline Youngest child 3-6 yrs & 0.326 & -0.191 & 0.247 & -0.024 & 0.055 & -0.035 & 0.097 & 0.003 & 0.124 & 0.024 & 0.126 & -0.150 \\
\hline & $(0.042)$ & $(0.035)$ & $(0.030)$ & $(0.020)$ & $(0.014)$ & $(0.012)$ & $(0.026)$ & $(0.027)$ & $(0.025)$ & $(0.027)$ & $(0.068)$ & $(0.065)$ \\
\hline Youngest child 7-17 yrs & 0.297 & -0.019 & 0.175 & 0.072 & 0.023 & -0.019 & 0.129 & 0.063 & 0.021 & 0.051 & 0.221 & -0.015 \\
\hline & $(0.028)$ & $(0.025)$ & $(0.023)$ & $(0.016)$ & $(0.013)$ & $(0.011)$ & $(0.021)$ & $(0.023)$ & $(0.019)$ & $(0.022)$ & $(0.051)$ & $(0.055)$ \\
\hline Number of children/10 & -0.160 & -0.115 & -0.063 & -0.121 & -0.053 & -0.052 & -0.046 & -0.103 & -0.064 & -0.034 & -0.058 & -0.087 \\
\hline & $(0.014)$ & $(0.013)$ & $(0.011)$ & $(0.007)$ & $(0.004)$ & $(0.003)$ & $(0.007)$ & $(0.007)$ & $(0.006)$ & $(0.006)$ & $(0.020)$ & $(0.022)$ \\
\hline
\end{tabular}


Table B2. Results from estimation of wage equation.

\begin{tabular}{|c|c|c|c|c|c|c|c|c|c|c|c|c|}
\hline & \multicolumn{2}{|c|}{ Denmark } & \multicolumn{2}{|c|}{ Nordic countries } & \multicolumn{2}{|c|}{ Turkey } & \multicolumn{2}{|c|}{ Africa } & \multicolumn{2}{|c|}{ Pakistan } & \multicolumn{2}{|c|}{ India \& Sri Lanka } \\
\hline & Males & Females & Males & Females & Males & Females & Males & Females & Males & Females & Males & Females \\
\hline \multirow[t]{2}{*}{ Constant 1} & 4.030 & 3.847 & 3.723 & 3.880 & 4.079 & 4.003 & 4.275 & 4.584 & 4.328 & 4.448 & 4.167 & 4.399 \\
\hline & $(0.024)$ & $(0.024)$ & $(0.023)$ & $(0.018)$ & $(0.056)$ & $(0.012)$ & $(0.031)$ & $(0.048)$ & $(0.030)$ & $(0.059)$ & $(0.072)$ & $(0.044)$ \\
\hline \multirow[t]{2}{*}{ Constant 2} & 4.408 & 4.162 & 4.297 & 4.321 & 4.419 & 4.423 & 4.769 & 5.096 & 4.776 & 4.974 & 4.685 & 4.771 \\
\hline & $(0.024)$ & $(0.024)$ & $(0.023)$ & $(0.019)$ & $(0.005)$ & $(0.011)$ & $(0.031)$ & $(0.049)$ & $(0.029)$ & $(0.059)$ & $(0.073)$ & $(0.045)$ \\
\hline \multirow[t]{2}{*}{ Primary education } & & & -0.125 & -0.055 & -0.037 & -0.081 & -0.021 & -0.123 & -0.025 & -0.066 & 0.015 & -0.092 \\
\hline & & & $(0.007)$ & $(0.004)$ & $(0.004)$ & $(0.007)$ & $(0.009)$ & $(0.013)$ & $(0.009)$ & $(0.018)$ & $(0.014)$ & $(0.017)$ \\
\hline \multirow[t]{2}{*}{ Secondary education } & 0.157 & 0.116 & 0.035 & -0.047 & 0.004 & -0.152 & -0.054 & -0.186 & 0.005 & -0.253 & -0.044 & -0.022 \\
\hline & $(0.005)$ & $(0.006)$ & $(0.011)$ & $(0.007)$ & $(0.011)$ & $(0.017)$ & $(0.020)$ & $(0.020)$ & $(0.016)$ & $(0.026)$ & $(0.029)$ & $(0.028)$ \\
\hline \multirow{2}{*}{ Vocational education } & 0.090 & 0.034 & 0.015 & -0.037 & 0.072 & -0.154 & -0.029 & -0.160 & 0.004 & 0.042 & -0.011 & -0.021 \\
\hline & $(0.002)$ & $(0.003)$ & $(0.007)$ & $(0.005)$ & $(0.009)$ & $(0.016)$ & $(0.012)$ & $(0.017)$ & $(0.016)$ & $(0.026)$ & $(0.023)$ & (0.019) \\
\hline \multirow[t]{2}{*}{ Theoretical education } & 0.185 & 0.073 & 0.075 & 0.013 & -0.064 & -0.226 & 0.014 & -0.157 & -0.035 & -0.369 & 0.005 & 0.069 \\
\hline & $(0.003)$ & $(0.003)$ & $(0.005)$ & $(0.004)$ & $(0.011)$ & $(0.021)$ & $(0.011)$ & $(0.021)$ & $(0.031)$ & $(0.052)$ & $(0.019)$ & $(0.020)$ \\
\hline \multirow[t]{2}{*}{ Experience/100 } & 4.428 & 2.261 & 5.631 & 3.127 & 4.490 & 1.944 & 2.367 & 1.224 & 3.085 & 0.576 & 2.484 & 2.996 \\
\hline & $(0.188)$ & $(0.148)$ & $(0.176)$ & $(0.130)$ & $(0.115)$ & $(0.140)$ & $(0.215)$ & $(0.310)$ & $(0.224)$ & $(0.319)$ & $(0.544)$ & $(0.441)$ \\
\hline \multirow[t]{2}{*}{ Experience $(5+y r s) / 100$} & -3.477 & -1.860 & -6.175 & -2.836 & -4.635 & -2.064 & -0.803 & -1.762 & -2.946 & -0.323 & -1.082 & -3.025 \\
\hline & $(0.259)$ & $(0.202)$ & $(0.273)$ & $(0.209)$ & $(0.186)$ & $(0.236)$ & $(0.357)$ & $(0.549)$ & $(0.377)$ & $(0.529)$ & $(0.862)$ & $(0.738)$ \\
\hline \multirow[t]{2}{*}{ Experience $(10+y r s) / 100$} & 0.052 & 0.786 & 1.156 & 0.548 & 1.001 & -0.216 & -0.482 & 1.920 & 0.259 & -0.071 & 0.198 & 1.208 \\
\hline & $(0.109)$ & $(0.094)$ & $(0.192)$ & $(0.156)$ & $(0.166)$ & $(0.237)$ & $(0.297)$ & $(0.517)$ & $(0.354)$ & $(0.574)$ & $(0.613)$ & $(0.569)$ \\
\hline \multicolumn{3}{|l|}{ Years since migration } & -3.525 & -1.360 & -1.257 & -0.067 & -0.342 & -1.012 & 2.321 & -0.221 & 0.115 & -0.709 \\
\hline$/ 100$ & & & $(0.237)$ & $(0.164)$ & $(0.180)$ & $(0.138)$ & $(0.293)$ & $(0.431)$ & $(0.430)$ & $(0.317)$ & $(0.748)$ & $(0.606)$ \\
\hline \multicolumn{3}{|l|}{ Yrs since migr $(5+y r s)$} & 3.662 & 1.240 & 1.439 & 0.917 & -0.076 & 1.279 & -1.303 & 0.020 & -0.685 & -0.149 \\
\hline \multicolumn{3}{|l|}{$/ 100$} & $(0.346)$ & $(0.238)$ & $(0.246)$ & $(0.241)$ & $(0.441)$ & $(0.630)$ & $(0.618)$ & $(0.263)$ & $(1.141)$ & $(0.886)$ \\
\hline \multicolumn{3}{|l|}{ Yrs since migr (10+yrs) } & 0.406 & 0.915 & 0.814 & 0.438 & 0.406 & 1.628 & 1.510 & 0.803 & 1.765 & 1.738 \\
\hline \multicolumn{3}{|l|}{$/ 100$} & $(0.204)$ & $(0.134)$ & $(0.129)$ & $(0.164)$ & $(0.288)$ & $(0.385)$ & $(0.323)$ & $(0.311)$ & $(0.619)$ & $(0.479)$ \\
\hline \multirow[t]{2}{*}{ Unemployment } & 0.584 & 1.042 & 1.673 & 1.986 & 1.954 & 3.981 & 0.763 & 2.066 & 4.014 & 2.293 & 2.572 & 1.658 \\
\hline & $(0.047)$ & $(0.053)$ & $(0.088)$ & $(0.066)$ & $(0.074)$ & $(0.111)$ & $(0.081)$ & $(0.207)$ & $(0.155)$ & $(0.205)$ & $(0.257)$ & $(0.237)$ \\
\hline Single & -0.029 & 0.008 & -0.039 & 0.015 & 0.030 & -0.044 & 0.035 & -0.007 & -0.019 & -0.127 & -0.025 & 0.018 \\
\hline & $(0.002)$ & $(0.003)$ & $(0.004)$ & $(0.003)$ & $(0.004)$ & $(0.006)$ & $(0.006)$ & $(0.009)$ & $(0.007)$ & $(0.011)$ & $(0.013)$ & $(0.013)$ \\
\hline High level salaried & 0.131 & 0.145 & 0.163 & 0.124 & 0.028 & 0.054 & 0.108 & 0.056 & 0.086 & 0.110 & 0.164 & 0.034 \\
\hline & $(0.003)$ & $(0.003)$ & $(0.005)$ & $(0.004)$ & $(0.006)$ & $(0.008)$ & $(0.007)$ & $(0.011)$ & $(0.010)$ & $(0.011)$ & $(0.014)$ & $(0.014)$ \\
\hline Low level salaried & -0.021 & 0.028 & 0.018 & 0.035 & 0.004 & -0.013 & -0.002 & -0.033 & -0.061 & -0.024 & -0.076 & -0.030 \\
\hline & $(0.004)$ & $(0.003)$ & $(0.006)$ & $(0.004)$ & $(0.004)$ & $(0.005)$ & $(0.007)$ & $(0.008)$ & $(0.008)$ & $(0.009)$ & $(0.016)$ & $(0.011)$ \\
\hline Skilled & 0.037 & 0.075 & 0.038 & 0.013 & -0.071 & -0.075 & -0.027 & -0.025 & -0.078 & -0.114 & -0.056 & -0.024 \\
\hline & $(0.003)$ & $(0.008)$ & $(0.008)$ & $(0.008)$ & $(0.005)$ & $(0.011)$ & $(0.008)$ & $(0.016)$ & $(0.010)$ & $(0.026)$ & $(0.018)$ & $(0.026)$ \\
\hline Missing occupation & -0.078 & -0.074 & 0.078 & -0.049 & -0.134 & -0.100 & -0.118 & -0.115 & -0.161 & -0.094 & -0.162 & -0.126 \\
\hline & $(0.004)$ & (0.004) & $(0.005)$ & $(0.004)$ & $(0.004)$ & $(0.005)$ & $(0.006)$ & $(0.008)$ & $(0.007)$ & $(0.011)$ & $(0.015)$ & $(0.013)$ \\
\hline Age/100 & 2.169 & 2.842 & 4.251 & 2.789 & 2.857 & 2.474 & 1.789 & 0.582 & -0.020 & 2.101 & 1.472 & 0.755 \\
\hline & $(0.112)$ & $(0.117)$ & $(0.110)$ & $(0.096)$ & $(0.069)$ & $(0.092)$ & $(0.190)$ & $(0.279)$ & $(0.112)$ & $(0.338)$ & $(0.382)$ & $(0.273)$ \\
\hline Age squared/10000 & -2.845 & -3.332 & -4.056 & -2.815 & -3.238 & -1.762 & -1.358 & -0.200 & 0.640 & -1.863 & -1.149 & -0.386 \\
\hline & $(0.135)$ & $(0.141)$ & $(0.133)$ & $(0.125)$ & $(0.110)$ & $(0.145)$ & $(0.258)$ & $(0.389)$ & $(0.167)$ & $(0.460)$ & $(0.502)$ & $(0.378)$ \\
\hline
\end{tabular}




\begin{tabular}{|c|c|c|c|c|c|c|c|c|c|c|c|c|}
\hline$\sigma_{\varepsilon}$ & $\begin{array}{c}0.066 \\
(0.000)\end{array}$ & $\begin{array}{c}0.069 \\
(0.000)\end{array}$ & $\begin{array}{c}0.422 \\
(0.001)\end{array}$ & $\begin{array}{c}0.358 \\
(0.001)\end{array}$ & $\begin{array}{c}0.384 \\
(0.001)\end{array}$ & $\begin{array}{c}0.442 \\
(0.001)\end{array}$ & $\begin{array}{c}0.461 \\
(0.001)\end{array}$ & $\begin{array}{c}0.467 \\
(0.002)\end{array}$ & $\begin{array}{c}0.490 \\
(0.001)\end{array}$ & $\begin{array}{c}0.494 \\
(0.002)\end{array}$ & $\begin{array}{c}0.404 \\
(0.002)\end{array}$ & $\begin{array}{c}0.343 \\
(0.002)\end{array}$ \\
\hline \multirow[t]{2}{*}{$\rho$} & -0.063 & -0.456 & -0.720 & -0.736 & -0.887 & -0.956 & -0.893 & -0.933 & -0.934 & -0.943 & -0.849 & -0.849 \\
\hline & $(0.014)$ & $(0.008)$ & (0.004) & $(0.003)$ & $(0.001)$ & $(0.001)$ & $(0.002)$ & $(0.002)$ & $(0.002)$ & $(0.002)$ & $(0.007)$ & (0.008) \\
\hline \multirow[t]{2}{*}{$\mathrm{P}_{11}$} & 0.243 & 0.121 & 0.147 & 0.100 & 0.060 & 0.011 & 0.061 & 0.058 & 0.031 & 0.013 & 0.098 & 0.119 \\
\hline & (0.009) & $(0.009)$ & $(0.009)$ & $(0.007)$ & $(0.005)$ & $(0.003)$ & $(0.007)$ & $(0.010)$ & (0.006) & $(0.007)$ & (0.019) & $(0.021)$ \\
\hline \multirow[t]{2}{*}{$P_{12}$} & 0.126 & 0.250 & 0.373 & 0.381 & 0.629 & 0.736 & 0.646 & 0.597 & 0.641 & 0.696 & 0.469 & 0.499 \\
\hline & $(0.008)$ & $(0.010)$ & $(0.010)$ & $(0.008)$ & $(0.007)$ & $(0.007)$ & $(0.009)$ & $(0.014)$ & $(0.011)$ & $(0.013)$ & $(0.024)$ & $(0.026)$ \\
\hline \multirow[t]{2}{*}{$\mathrm{P}_{21}$} & 0.431 & 0.471 & 0.333 & 0.379 & 0.223 & 0.219 & 0.226 & 0.309 & 0.268 & 0.270 & 0.330 & 0.319 \\
\hline & $(0.008)$ & $(0.008)$ & (0.006) & $(0.006)$ & $(0.005)$ & $(0.007)$ & $(0.007)$ & $(0.011)$ & (0.009) & $(0.011)$ & (0.019) & $(0.020)$ \\
\hline \multirow[t]{2}{*}{$\mathrm{P}_{22}$} & 0.199 & 0.159 & 0.147 & 0.140 & 0.088 & 0.034 & 0.067 & 0.040 & 0.060 & 0.022 & 0.103 & 0.063 \\
\hline & $(0.006)$ & $(0.006)$ & $(0.005)$ & $(0.004)$ & $(0.004)$ & $(0.003)$ & $(0.004)$ & $(0.004)$ & $(0.005)$ & $(0.003)$ & $(0.012)$ & $(0.011)$ \\
\hline
\end{tabular}




\section{IZA Discussion Papers}

\author{
No. Author(s) \\ 290 \\ D. A. Cobb-Clark \\ M. D. Connolly \\ C. Worswick
}

291

R. T. Riphahn

292

E. Wasmer

293

294

D. Cobb-Clark

T. F. Crossley

295

296
F. Duffy
P. P. Walsh

H. S. Nielsen

M. Rosholm

N. Smith

L. Husted

297

J. C. van Ours

J. Veenman

298

P. Telhado Pereira

P. Silva Martins

299
G. Brunello
C. Lucifora
R. Winter-Ebmer

300
A. Stutzer
R. Lalive

301
Title

Area

Date

The Job Search and Education Investments of

1

04/01 Immigrant Families

Cohort Effects in the Educational Attainment of Second Generation Immigrants in Germany:

An Analysis of Census Data

Between-group Competition in the Labor Market and the Rising Returns to Skill: US and France 1964-2000

Gender, Comparative Advantage and Labor

05/01

Market Activity in Immigrant Families

Estimating the Effect of Unemployment

3

05/01

Insurance Compensation on the Labor Market

Histories of Displaced Workers

Individual Pay and Outside Options:

4

Evidence from the Polish Labour Force Survey

05/01

Intergenerational Transmissions and the Schoolto-Work Transition of $2^{\text {nd }}$ Generation Immigrants

05/01

The Educational Attainment of Second

1

05/01

Generation Immigrants in The Netherlands

Returns to Education and Wage Equations

5

$06 / 01$

The Wage Expectations of European College

5

$06 / 01$ Students

5

06/01

Searching and Subjective Well-Being

Economic and Social Perspectives of Immigrant Children in Germany 

H. Bonin
G. Abío
E. Berenguer
J. Gil
C. Patxot Monetary Appraisal 

A. Frederiksen
E. K. Graversen
N. Smith

324

M. Pflüger

325
R. A. Hart
J. R. Malley
U. Woitek

Trade, Technology and Labour Markets: 

A. lbourk
B. Maillard

The Matching Efficiency of Regional Labour Models 
$\begin{array}{ll}345 & \text { J. Hampe } \\ \text { M. Steininger }\end{array}$

346

L. Locher

347

M. Lofstrom

F. D. Bean

348

S. Neuman

A. Ziderman

349

J. T. Addison

P. Portugal

350

J. T. Addison

P. Portugal

351

J. D. Brown

J. S. Earle

352

J. T. Addison

J. S. Heywood

X. Wei

353

T. Bauer

S. Bender

354

J. Kluve

355

J. Kluve

H. Lehmann

C. M. Schmidt

356

C. Heady

T. Mitrakos

P. Tsakloglou

$357 \quad$ C. Knoppik

T. Beissinger

358

T. Beissinger

O. Buesse
Survival, Growth, and Interfirm Collaboration of

5

Start-Up Companies in High-Technology

Industries: A Case Study of Upper Bavaria

The Determination of a Migration Wave Using

1

Ethnicity and Community Ties

Labor Market Conditions and Post-Reform

3

Declines in Welfare Receipt Among Immigrants

Can Vocational Education Improve the Wages of

5

Minorities and Disadvantaged Groups? The

Case of Israel

Job Search Methods and Outcomes

1

$08 / 01$

Unemployment Duration: Competing and

1

08/01

Defective Risks

Gross Job Flows in Russian Industry Before and

4

$08 / 01$

After Reforms: Has Destruction Become More

Creative?

Unions and Plant Closings in Britain: New 1

$08 / 01$

Evidence from the 1990/98 WERS

Flexible Work Systems and the Structure of

5

$08 / 01$

Wages: Evidence from Matched Employer-

Employee Data

On the Role of Counterfactuals in Inferring

Causal Effects of Treatments

6

Disentangling Treatment Effects of Polish Active Labor Market Policies: Evidence from Matched Samples

The Distributional Impact of Social Transfers in the European Union: Evidence from the ECHP

How Rigid are Nominal Wages?

1

09/01

Evidence and Implications for Germany

Bismarck versus Beveridge: Which Unemploy-

3

09/01 ment Compensation System is More Prone to Labor Market Shocks?

A Simple, Analytically Solvable Chamberlinian

2

09/01 


\section{S. J. Trejo}

364 M. Jäntti

$$
\text { S. P. Jenkins }
$$

Examining the Impact of Macro-Economic 3 Conditions on Income Inequality 